\title{
Mebendazole's Conformational Space and its Predicted Binding to Human Heat-Shock Protein 90
}

\author{
Walter Fiedler ${ }^{1}$, Fabian Freisleben ${ }^{1}$, Jasmin Wellbrock $^{1}$, and Karl N. Kirschner*2 \\ ${ }^{1}$ Department of Oncology, Hematology and Bone Marrow Transplantation with Section \\ Pneumology, Hubertus Wald University Cancer Center, University Medical Center \\ Hamburg-Eppendorf, 20251 Hamburg, Germany \\ ${ }^{2}$ Department of Computer Science, Hochschule Bonn-Rhein-Sieg, University of Applied \\ Sciences, 53757 Sankt Augustin, Germany
}

September 28, 2021

\begin{abstract}
Recent experimental evidence suggest that mebendazole, a popular antiparasitic drug, binds to heat shock protein 90 (Hsp90) and inhibit acute myeloid leukemia cell growth. In this study we use quantum mechanics (QM), molecular similarity and molecular dynamics (MD) calculations to predict possible binding poses of mebendazole to the adenosine triphosphate (ATP) binding site of Hsp90. Extensive conformational searches and minimization of the five tautomers of mebendazole using MP2/aug-cc-pVTZ theory level resulting in 152 minima being identified. Mebendazole-Hsp90 complex models were created using the QM optimized conformations and protein coordinates obtained from experimental crystal structures that were chosen through similarity calculations. Nine different poses were identified from a total of $600 \mathrm{~ns}$ of explicit solvent, all-atom MD simulations using two different force fields. All simulations support the hypothesis that mebendazole is able to bind to the ATP binding site of Hsp90.
\end{abstract}

\section{Introduction}

Heat shock protein 90 (Hsp90) is a chaperone protein that enables the functionality of numerous client proteins by facilitating their maturation and stabilizing their protein structure $[1,2]$. Signalling proteins switch between conformational states depending on their activation. Due to this intrinsic structural instability, proteins being essential for the cell's signalling network, such as kinases, hormone receptors, and transcription factors, are particularly dependent on HSP90 [3]. Dysregulation of cellular signalling networks is a central characteristic of cancer cells [4] and many client proteins of Hsp90 are critically involved in oncogenesis [5]. Accordingly, Hsp90 has been indicated to play a role in cancer [6-9]. Altered expression levels of Hsp90 have been found in patients with medulloblastoma [10] and breast cancer [11], while binding studies in cells show growth inhibition of various tumors [12-15].The development of resistance is a major obstacle in cancer therapy [16]. As a highly specialized chaperone, Hsp90 has found to be crucial in enabling adaptability and heterogeneity of cancers [17] and growing evidence suggests Hsp90 inhibitors might be the key in limiting the ability of cancer cells to adapt and evolve drug resistance $[16,17]$.

Of specific interest is Hsp90's N-terminal adenosine triphosphate (ATP) binding site [18] that shows the ability to bind many ligands. A substantial body of research exists that computationally investigates this site, primarily with the goal of understanding the binding of ligands [19-26] or for predicting new active compounds [27-38] for further study. It was also the focus of Drug Design Data Resource's first Grand Challenge [39-46].

Mebendazole (methyl 5-benzoyl-2-benzimidazole-carbamate) is an established antiparasitic drug that has been indicated as a possible repurposing candidate for cancer treatment [47-53], including acute myeloid leukemia (AML) [54-56]. Mebendazole has been used as a medicine for several decades, has a well established pharmacology [57] and is listed as an essential medicine by the World Health Organization [58]. Experimentally, four small-molecule crystal structures of mebendazole exist in the Cambridge Crystallographic Data Centre database [59] that provide unique conformations for one protonated [60] and three neutral [61-63] species. An experimental crystal structure of mebendazole bound to a protein has never been reported. However, few computational predictions have been made for mebendazole's binding to various proteins [64-67].

*Corresponding author: karl.kirschner@h-brs.de 
Recently, Fiedler and colleagues experimentally showed that mebendazole is a potent Hedgehog signaling inhibitor that acts by inducing proteasomal degradation of glioma-associated oncogene (GLI) transcription factors [56]. GLI transcription factors drive a genetic program being fundamental for the pathophysiology of leukemia initiating cells that are responsible for therapy failure and tumor relapse due to their chemotherapy resistance [68]. Targeted inhibition of GLI1 and GLI2 mediates anti-leukemic effects in vitro and in vivo. Moreover, high GLI1 and GLI2 expression has been shown to represent a negative prognostic marker in AML [69]. Specifically, there is strong evidence that mebendazole binds to Hsp70 or Hsp90, and consequently inhibits their chaperone activity that is needed for maintaining the protein stability of GLI transcription factors and preventing their degradation. This mebendazole-induced inhibition leads to strong, does-dependent anti-leukemic effects on AML cells. In this contribution, motivated by this recent experimental finding, we predict the binding and dynamics of mebendazole to the ATP site of Hsp90 using quantum mechanics and molecular dynamics simulations. The resulting data indicates that mebendazole forms a stable interaction with Hsp90, with the likelihood of adopting different poses within the binding pocket.

\section{Methodology}

\subsection{Quantum Optimization}

Mebendazole Conformations There are five possible tautomers for mebedazole, as shown in Figure 1, which result in a large possible conformational space that needs sampling. Mebendazole can be separated into three distinct chemical units: a carbamate, an imidazole and a biphenyl ketone (i.e. benzophenone). The tautomerization occurs within the carbamate and imidazole groups. Mebendazole tautomers 1-3 have five flexible torsion angles, (Figure 2, labeled a-e) that define the conformational space to be explored. An additional torsion angle (labeled $\mathrm{f}$ ) is required for tautomers 4 and 5 due to the alcohol functionality. Conceptually, two sets of iterations were performed for generating conformations. The first set consisted of setting [d,e] torsions to $\left[150^{\circ}, 150^{\circ}\right]$ and to $\left[-150^{\circ},-150^{\circ}\right]$, and subsequent iterations through the remaining torsions. Analysis of the resulting geometries allowed us to reduce the angles sampled for the creation of the second set. For example, it was observed that torsion c sampled only $0^{\circ}$ and $180^{\circ}$ for tautomer 3 , allowing us to remove the $\pm 60^{\circ}, \pm 90^{\circ}$, $\pm 120^{\circ}$ from its list. These torsion angles were systematically set to all possible combination using the values given in Table 1.

Table 1. Torsion angles (degrees) used for creating input conformations for QM optimizations. ${ }^{\mathrm{a}}$

\begin{tabular}{ccc}
\hline \hline Torsion & Set 1 & Set 2 \\
\hline $\mathrm{a}$ & $0, \pm 60, \pm 90, \pm 120,180$ & $0, \pm 60, \pm 120,180$ \\
$\mathrm{~b}$ & $0, \pm 60, \pm 90, \pm 120,180$ & $0, \pm 60, \pm 120,180$ \\
$\mathrm{c}$ & $0, \pm 60, \pm 90, \pm 120,180$ & 0,180 \\
$\mathrm{~d}$ & \pm 150 & \pm 35 \\
$\mathrm{e}$ & \pm 150 & \pm 30 \\
$\mathrm{f}$ & $0, \pm 60, \pm 90, \pm 120,180$ & $0, \pm 60, \pm 120,180$ \\
\hline \hline
\end{tabular}

All input conformations were optimized using HF/6-31G(d) theory [70]. Frequency analyses were subsequently performed to verify that the resulting structures were potential energy minima. All structurally unique minima were further optimized at MP2/aug-cc-pVTZ (AVTZ) theory level [71,72], correlating only the valence electrons. Density-fitted algorithm [73-75] was utilized with the appropriate corresponding auxiliary basis sets [76, 77]. All optimizations were performed using $\mathrm{C} 1$ molecular symmetry and until the following convergence criteria were met (i.e. gau_tight): Max. Force: $1.5 \times 10^{-5}$, RMS Force: $1.0 \times 10^{-5}$, Max. Disp.: $6.0 \times 10^{-5}$, RMS Disp.: $4.0 \times 10^{-5}$. The Psi4 software (v. 1.2.1) was used for all QM calculations [78].

\subsection{Identification and preparation of protein targets and their bound ligands}

The Protein Data Bank (rcsb.org) [79,80] was searched for HPS90 proteins, specifying X-ray structures only and human organism as the material source. All associated ligands found by the search were downloaded (a single SDF-formatted file) applying the default setting of RCSB (e.g. no hydrogen, exclude "instances with missing heavy atoms"). This list was further curated by removing small-sized and transition metal containing ligands (i.e. magnesium ions, chloride ions, sodium ions, nickle (II) ions, calcium ions, phosphate ion, sulfate ion, carbonate ion, acetate ions, acetic acid, formic acid, thiocyanate ion, dimethyl sulfoxide, ethylene glycol, 
<smiles>COC(=O)Nc1nc2cc(C(=O)c3ccccc3)ccc2[nH]1</smiles>

1<smiles>COC(=O)Nc1nc2ccc(C(=O)c3ccccc3)cc2[nH]1</smiles>

2<smiles>COC(=O)/N=c1\[nH]c2ccc(C(=O)c3ccccc3)cc2[nH]1</smiles>

3<smiles>CO/C(O)=N/c1nc2cc(C(=O)c3ccccc3)ccc2[nH]1</smiles>

4<smiles>CO/C(O)=N/c1nc2ccc(C(=O)c3ccccc3)cc2[nH]1</smiles>

5

Figure 1: The five tautomers of mebendazole [62].

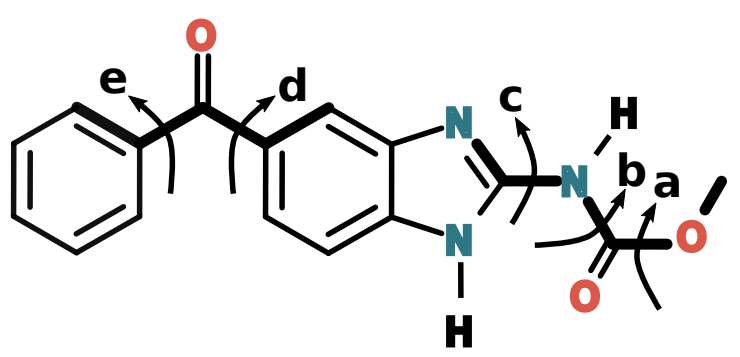

1

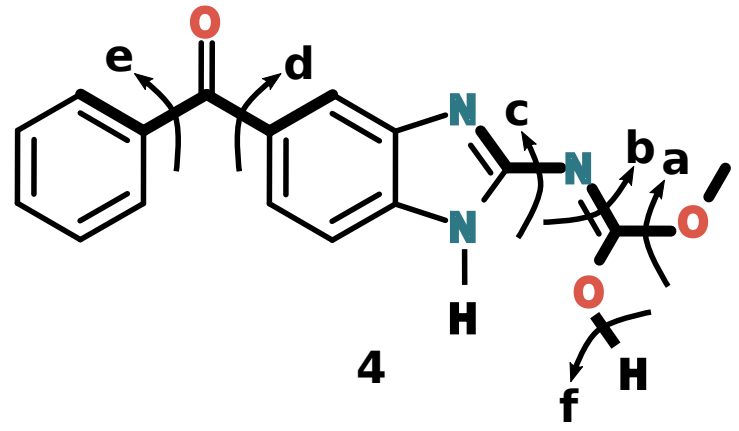

Figure 2: The flexible torsion angles (i.e. a-f) of mebendazole, represented by tautomers 1 and 4 . The bond sequence used for defining the torsions are shown with thicker lines. Note that torsions a and b are defined using the same atoms for all tautomers.

ethane-1,2-diol, glycerol, cobalt hexammine (III)). This resulted in a final seletion of 300 ligands. The resulting crystal and ligands ID codes can be found in Tables S1 and S2.

Ligand Preparation Open Babel $[81,82]$ was used to separate the crystallized ligands and convert them to PDB-formatted files. Hydrogen atoms were automatically added using either Open Babel or PyMOL [83]. Manual inspections were subsequently done and adjustment were made to correct any improperly add hydrogens. Adjustment were not made to assigned tautomer, or for correcting nitrogen hybridization (planar vs pyramidal).

Protein Preparation MolProbity was used to analyze, modify side-chain orientations (i.e. ASP, GLU, HIS) and add hydrogen to the protein crystals that were used in the MD simulations (i.e. 2WI6, 2BT0 and 4W7T; 
see Results section) [84-87].

\subsection{Similarity}

To compute the similarity, one requires reliable geometries and electrostatics. AMBER's antechamber program was used to generate AM1-BCC partial atomic charges for both crystallized ligands and the mebendazole tautomers - thus, providing a consistent methodology for electrostatic comparison. For mebendazole the MP2/AVTZ geometries were used, while for the crystallized ligands AM1 optimizations were performed. For ligands containing phosphate functional groups, a formal molecular charge of -2 was assigned. All other ligands were individually assigned a charge state of $0,-1$ or +1 . The ShaEP program was used to compute all pairwise similarities [88].

\subsection{Molecular Mechanics and Dynamics}

Partial Atomic Charges The partial atomic charges for the tautomer 1 and 2 of mebendazole were separately computed using the RESP [89,90] methodology as implemented in Psi4 [91]. Specifically, Connolly molecular electrostatic surfaces were generated at the HF/6-31G(d) theory level, using the MP2/AVTZ optimized geometries. A two-stage procedure was used. In the first stage, a 0.0005 a.u. restraint was used without enforcing charge equivalency between rotationally equivalent atoms. In the second stage aliphatic carbons and their hydrogens were refitted using a 0.001 a.u. restraint, and charge equivalency was enforced (i.e. phenyl ring atoms, methyl hydrogens). During both stages, four conformations were used with intermolecular constraint to ensure that the resulting single partial atomic charge set optimally reproduce all four conformations. For each tautomer, the four conformations with the lowest unique relative energies (i.e. conformations 1, 3, 5 and 7) were used (see Table 2) to compute the final averaged charge set. The resulting partial atomic charges can be found within the two mol2 files of SI material.

Molecular Dynamics The ff14SB [92] and FB15 [93] force fields were used to model the protein, while the gaff2 [94] force field was used for modeling mebendazol. For the validation of gaff2, the MP2/AVTZ optimized geometries were used as input into the gas-phase molecular mechanics optimizations. Explicit water periodic box simulations were also performed using the TIP3P and force balance water models, as recommended for use with the ff14SB and FB15 protein force fields, respectively. The SLTCAP software was used to compute the number of ions need for modeling a biological salt concentration of $150 \mathrm{mM}$ [95]. In total, $32 \mathrm{Cl}-$ and $30 \mathrm{Na}+$ atoms, plus 9844 (2bt0 model) to 10121 (2wi6) water molecules, were added to the models using AmberTools19's tLEaP algorithm [96]. Minimization were performed first by constraining (500.0 kcal $\cdot \mathrm{mol}^{-1} \cdot \AA^{2}$ harmonic constraint) the protein and mebendazol, followed by a minimization of the entire model to a convergence criterion of 0.5 $\mathrm{kcal} \cdot \mathrm{mol}^{-1} \cdot \AA^{-1}$.

The models were heated from $0-310 \mathrm{~K}$ in $1.0 \mathrm{~ns}$ under constant volume conditions, followed by a 5 ns constant pressure equilibrium simulation using a Berendsen barostat and isotropic position scaling. Constant volume production simulations were subsequently ran for $110 \mathrm{~ns}$. Langevin dynamics [97] with a collision frequency (i.e. gamma_ln) of $1.0 \mathrm{ps}^{-1}$ [98] was used for temperature regulation. A nonbonded cutoff of $8.0 \AA$ was used is all explicit simulations, with Particle Mesh Ewald [99] used to for modelling the nonbonded interactions at longer distances. Covalently bound hydrogen atoms were constrained using the Shake algorithm [100]. A random number generator (i.e. $\mathrm{ig}=-1$ ) was used to create the seed value for all Langevin dynamics. A 2 fs per iteration time step was employed. Molecular dynamics simulations were performed using AMBER16's CUDA version of PMEMD [101, 102].

MD Analysis The last $100 \mathrm{~ns}$ of each MD trajectory was analyzed using CPPTRAJ (v4.25.6) [103], with frame alignment performed via an RMSD calculation of the protein's heavy atoms. Waters that interact with mebendazole were identified using CPPTRAJ's 'watershell' command, with a default cutoff distances of $3.4 \AA$ specified. The mean of the resulting number of waters was then used to remove all but the closest water using the 'closest', 'outtraj' and 'parmstrip' commands.

Root-mean-squared fluctuations (RMSF) were computed for the protein's backbone heavy-atoms and a mass-weighted average was done to provide a single value per amino acid (i.e. CPPTRAJ's 'atomicfluc' command with 'byres' specified). The secondary structure was computed for each trajectory using the Define Secondary Structure of Proteins (DSSP) method [104] (i.e. CPPTRAJ's 'secstruct' command).

Cluster analyses were performed on RMSD protein-aligned trajectories that clustered the mebendazole position within the binding pocket. Hydrogen atoms were excluded from the alignment and clustering, as well as 2-4 amino acids at the proteins' termini due to their high fluctuations. Six independent hierarchical agglomerative clustering analyses were performed on each trajectory using integer epsilon values that incrementally ranged from 2.0 to 7.0. Based on their resulting pSF (pseudo-F statistic) [105] - as measure for clustering quality the results using the best epsilon value for a given trajectory were focused upon. The resulting binding-pose 
trajectories were subsequently used for the remaining analyses. The exception to this are the 4W7T trajectories where the clustering did not yield meaningful results (see below), and thus their last 100 ns were used.

The amino acids that closely interact with mebendazole in the binding pocket were identified using CPPTRAJ's 'mask' command and a heavy-atom cutoff $3.4 \AA$. The resulting list was filtered to identify only the amino acids that interacted with mebendazole for at least $50 \%$ of the frames for a given trajectory.

Spatial distribution analyses were performed on using the 'grid' command, which creates a histogram of the spatial positioning of desired molecular species using a defined gridded cube. A cell spacing of $0.5 \AA$ was specified and the resulting density was normalized. Spatial distributions were analyzed for the following three chemical groups: mebendazole, binding pocket amino acids and waters. Care was taken to ensure that analyses were performed specifically on trajectory portions that correspond to the most populated ligand binding motifs.

The binding energies $\left(\Delta E_{\text {bind }}\right)$ of mebendazole to Hsp90 were estimated through Molecular Mechanics/Poisson Boltzmann Surface Area (MM/PBSA) calculations using the MMPBSA.py [106] program. In all MM/PBSA calculations the entropy $(T \Delta S)$ was not computed, and thus our binding energies take the form $\Delta E_{\text {bind }}=$ $\Delta E_{\mathrm{MM}}+G_{\text {Solv }}$, where $\Delta E_{\mathrm{MM}}$ is the molecular mechanics energy difference between the complex and uncomplexed species. For each pose originating from the 2WI6 and 2BT0 simulations, $\Delta E_{\text {bind }}$ was computed using 100 equally spaced pose-specific frames, as identified during the cluster analysis. For the poses originating from the $4 \mathrm{~W} 7 \mathrm{~T}$ simulations, the last $70 \mathrm{~ns}$ of the trajectories were used as input. Note that the minimum possible time separating the sampled trajectory frames was $168 \mathrm{ps,} \mathrm{which} \mathrm{occurred} \mathrm{2BT0-ff14SB} \mathrm{pose} \mathrm{1.} \mathrm{MM/PBSA} \mathrm{was} \mathrm{performed}$ using both force field, which gave identical results. All water and salt ions were removed from the frames before computing $\Delta E_{\text {bind }}$. An implicit ionic strength of $0.1 \mathrm{mM}$ was specified in all MM/PBSA calculations, the atomic radii were set to mbond2 [107], and with all other parameters set to MMPBS.py's default values.

\section{Results}

\subsection{QM Mebendazole Optimizations}

Since all 5 tautomers of the drug (Figure 1) are possible candidate for binding to a protein's active site, conformational searches and subsequent QM optimizations were performed on all tautomers. All energetically unique structures occur in conformational isomeric pairs (see Table 2) that primarily arise from the different carbamate orientations relative to the benzophenone functionality. To clearly identify the conformations with respect to the tautomers, we will use the following nomenclature: $T_{\text {conf num. num. }}^{\text {taut num }}$.

The gas-phase conformational search using HF/6-31G(d) theory resulted in 94 pairs of conformational isomers (i.e. 188 spatially unique conformations). Subsequent MP2/AVTZ optimizations resulted in a total of 76 isomer pairs, whose relative energies are provided in Table 2 . The more stable MP2/AVTZ conformations (i.e. $<5$ $\left.\mathrm{kcal} \cdot \mathrm{mol}^{-1}\right)$ occur when mebendazole exists in its tautomer $1\left(\mathrm{~T}^{1}\right)$ and $2\left(\mathrm{~T}^{2}\right)$ form. In comparison to the three crystal structures of neutral mebendazole, $\mathrm{T}_{1}^{2}$ and $\mathrm{T}_{2}^{2}$, the most stable conformation pair, corresponds to Caira [61], Ferreira [63] and coworkers' crystal structures. In contrast, $\mathrm{T}_{1}^{1}$, one conformation from the second most stable pair, corresponds to Martins et al.'s crystal structure [62].

The agreement in geometries between the crystal and MP2/AVTZ structures are very good as seen in Table 3's RMSD values. The poorest agreement is between $\mathrm{T}_{1}^{2}$ and the oldest crystal structure, published in 1998, with a heavy-atom RMSD of $0.24 \AA$. For $\mathrm{T}_{2}^{2}$ and $\mathrm{T}_{1}^{1}$, their structures have heavy-atom RMSD values of 0.07 and $0.08 \AA$ to their respective crystal conformation. Collectively, the MP2/AVTZ results clearly demonstrates the complexity of the potential energy surface (PES) that mebendazole resides upon, with 152 unique conformations whose relative energies can extend $32 \mathrm{kcal} \cdot \mathrm{mol}^{-1}$ above the global minima. It is encouraging to see that the conformations of the most stable minima computed using a moderate electron correlation level with an extensive basis set coincides with experimental solid-state results, with very good agreement in the geometries themselves.

\subsection{Similarity Calculations}

The similarity between all mebendazole tautomers and their QM optimized conformations were computed $(11,476$ pairwise calculations), whose resulting index values ( $\max =0.92 ; \min =0.45 ;$ avg $=0.65)$ are shown in Figure 3. This figure illustrates the wide variety of geometric and electrostatic topologies that mebendazole could present to a protein for binding.

Since we have computed an extensive collection of reliable mebendazole conformations and 287 human Hsp90 crystal structures with diverse ligands bound to its ATP site, molecular similarity can also be used a) to make initial predictions for how mebendazole might bind to Hsp90 and b) to create initial structures for MD simulations. Towards these goals, the similarity index between the eight most stable mebendazole conformations (i.e. $\mathrm{T}_{1-4}^{1}, \mathrm{~T}_{1-4}^{2}$; Table 2) and the 300 ligands extracted from 287 crystal structures were computed. The choice to use the eight most stable mebendazole conformations, whose relative energies are within $0.6 \mathrm{kcal} \cdot \mathrm{mol}^{-1}$, was made based on the assumption that they are the most likely ones to be populated at body temperature. 
Table 2. Relative conformational energies $\left(\mathrm{kcal} \cdot \mathrm{mol}^{-1}\right)$ across all tautomers computed at the MP2/AVTZ theory level.

\begin{tabular}{|c|c|c|c|c|c|c|c|c|c|}
\hline \multicolumn{2}{|c|}{ Taut. 1} & \multicolumn{2}{|c|}{ Taut. 2} & \multicolumn{2}{|c|}{ Taut. 3} & \multicolumn{2}{|c|}{ Taut. 4} & \multicolumn{2}{|c|}{ Taut. 5} \\
\hline Conf. & Rel. E. & Conf. & Rel. E. & Conf. & Rel. E. & Conf. & Rel. E. & Conf. & Rel. E. \\
\hline 1,2 & 0.166 & 1,2 & 0.000 & 1,2 & 5.152 & 1,2 & 8.697 & 1,2 & 8.551 \\
\hline 3,4 & 0.610 & 3,4 & 0.272 & 3,4 & 5.351 & 3,4 & 9.147 & 3,4 & 8.936 \\
\hline 5,6 & 3.820 & 5,6 & 3.465 & 5,6 & 5.420 & 5,6 & 10.906 & 5,6 & 10.809 \\
\hline 7,8 & 4.352 & 7,8 & 3.932 & 7,8 & 5.498 & 7,8 & 11.215 & 7,8 & 11.100 \\
\hline 9,10 & 7.370 & 9,10 & 7.296 & 9,10 & 7.170 & 9,10 & 21.644 & 9,10 & 21.476 \\
\hline 11,12 & 7.725 & 11,12 & 7.450 & 11,12 & 7.488 & 11,12 & 21.983 & 11,12 & 21.858 \\
\hline 13,14 & 17.177 & 13,14 & 16.967 & 13,14 & 7.569 & 13,14 & 22.323 & 13,14 & 21.867 \\
\hline 15,16 & 17.311 & 15,16 & 17.072 & 15,16 & 7.605 & 15,16 & 22.585 & 15,16 & 22.238 \\
\hline 17,18 & 17.830 & 17,18 & 17.459 & 17,18 & 11.003 & 17,18 & 23.308 & 17,18 & 23.186 \\
\hline 19,20 & 17.945 & 19,20 & 17.535 & 19,20 & 11.093 & 19,20 & 23.325 & 19,20 & 23.208 \\
\hline & & & & 21,22 & 11.297 & 21,22 & 23.495 & 21,22 & 23.296 \\
\hline & & & & 23,24 & 11.356 & 23,24 & 23.585 & 23,24 & 23.336 \\
\hline & & & & & & 25,26 & 23.792 & 25,26 & 23.554 \\
\hline & & & & & & 27,28 & 23.835 & 27,28 & 23.574 \\
\hline & & & & & & 29,30 & 23.955 & 29,30 & 23.697 \\
\hline & & & & & & 31,32 & 24.304 & 31,32 & 23.794 \\
\hline & & & & & & 33,34 & 25.194 & 33,34 & 25.106 \\
\hline & & & & & & 35,36 & 25.427 & 35,36 & 25.262 \\
\hline & & & & & & 37,38 & 25.617 & 37,38 & 25.437 \\
\hline & & & & & & 39,40 & 25.835 & 39,40 & 25.619 \\
\hline & & & & & & 41,42 & 31.760 & 41,42 & 31.718 \\
\hline & & & & & & 43,44 & 32.262 & 43,44 & 31.997 \\
\hline
\end{tabular}

Table 3. All-atom (heavy-atom) RMSD between MP2/AVTZ optimized and experimental mebendazole structures for equivalent conformations.

\begin{tabular}{l|ccc}
\hline \hline & $\mathrm{T}_{1}^{1}$ & $\mathrm{~T}_{1}^{2}$ & $\mathrm{~T}_{2}^{2}$ \\
\hline Crystal (1998) [61] & & $0.265(0.236)$ & \\
Crystal (2009) [62] & $0.126(0.071)$ & & \\
Crystal (2010) [63] & & & $0.265(0.077)$ \\
\hline \hline
\end{tabular}




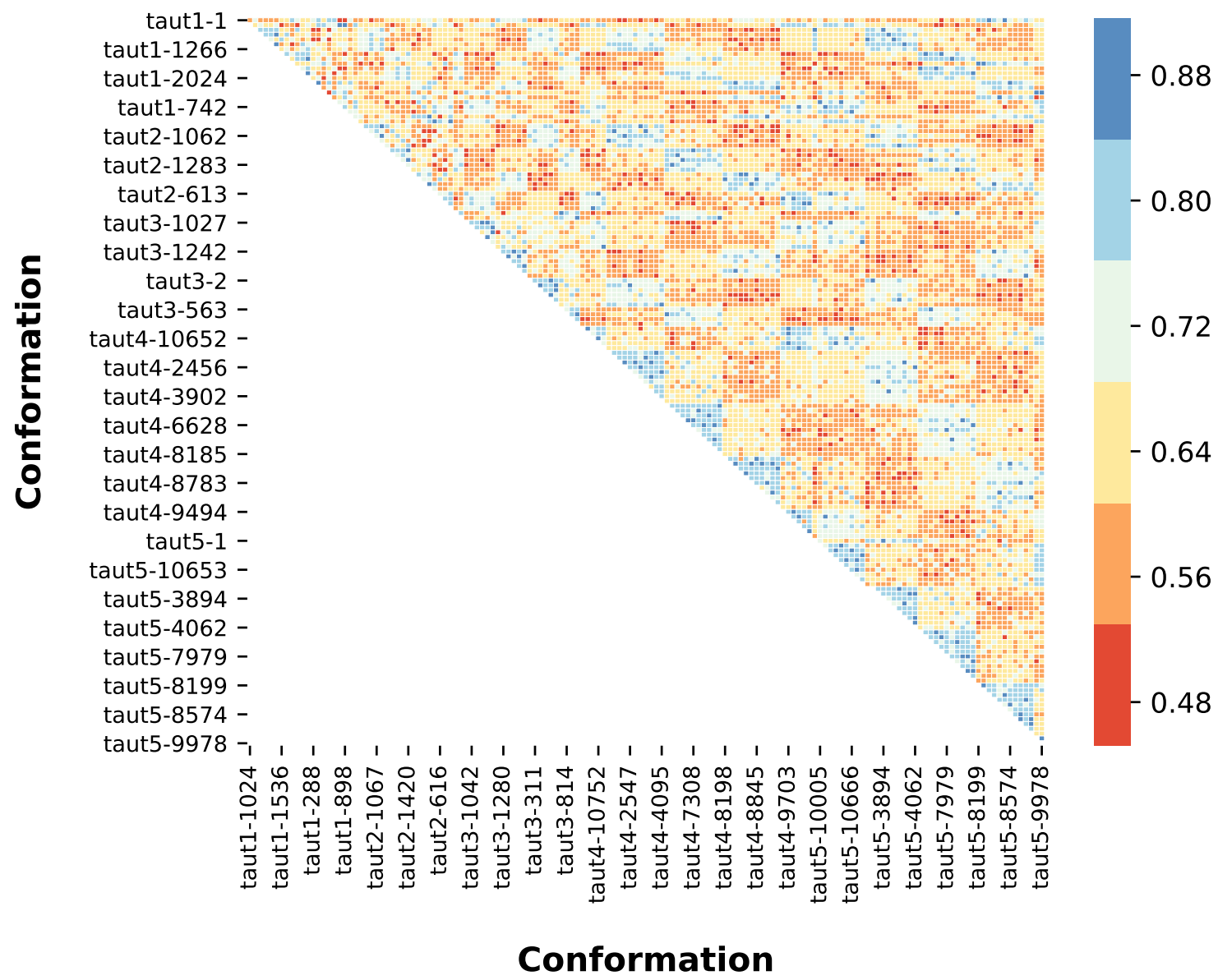

Figure 3: Similarity indexes (structure \& electrostatic) computed between all MP2/AVTZ//MP2/AVTZ mebendazole conformations. 

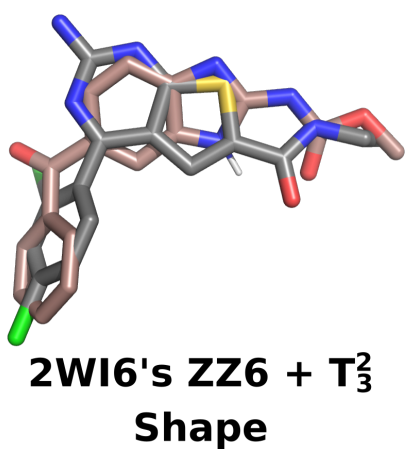

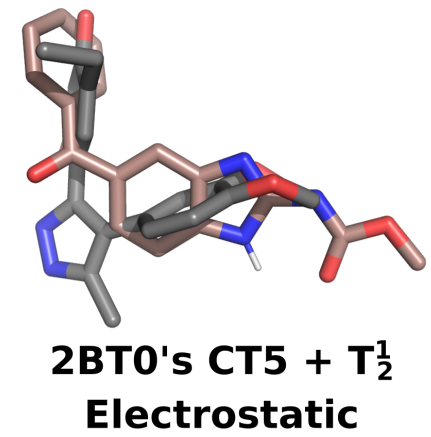

\section{W7T's 3JC + T/2 Shape \& Electrostatic}

Figure 4: The structure overlay of mebendazole (brown) with the resulting three most similar Hsp90 ligands (gray) as determined by Shape (index $=0.86$ ), Electrostatic (index $=0.59)$ and Shape \& Electrostatic (index $=0.69$ ) criteria. Apart from the imidazole's hydrogen, only the heavy atoms are displayed for simplicity.

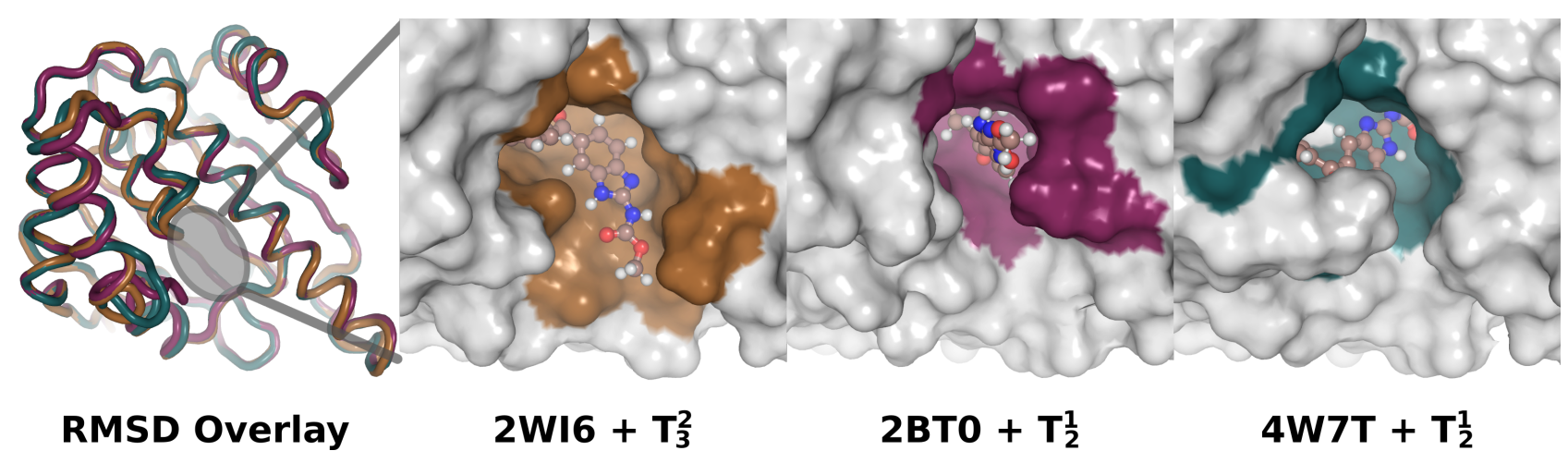

Figure 5: An RMSD overlay of the 2WI6 (orange), 2BT0 (purple), and 4W7T (blue-green) N-terminal domain of Hsp90. The ATP binding site with mebendazole (tautomers 1 and 2) replacing the crystal ligands as specified from the similarity calculations. The surface colors highlight the amino acids that are within $4 \AA$ (i.e. half of the MD nonbonded cutoff) of mebendazole. Shown are the mebendazole and protein structures with hydrogen atoms added and after molecular mechanics minimization.

The resulting indexes reveal that the most similar structures are $\mathrm{T}_{3}^{2}$ and $2 \mathrm{WI}$ 's ligand $\mathrm{ZZ6}$ (index=0.86), $\mathrm{T}_{2}^{1}$ and 2BT0's ligand CT5 (index=0.59), and $\mathrm{T}_{2}^{1}$ and 2BT0's ligand CT5 (index=0.59), respectively based on 1) shape, 2) electrostatic and 3) shape \& electrostatic criteria. The resulting structural overlay of mebendazole conformations with 2WI6, 2BT0 and 4W7T's ligands can be seen in Figure 4.

2WI6 [13], 2BT0 [108] and 4W7T [109] are well resolved crystal structure with resolutions of 2.18, 1.90 and $1.80 \AA$, and have chemically distinct ligand bound to Hsp90's ATP binding site [18]. A heavy-atom RMSD fit of these three crystallized proteins show that the structures are within $0.96-1.51 \AA$ of one another, indicating that the overall protein structures are similar. Even though the ligands bind to the ATP binding pock within in each protein, the binding pockets' topologies differs substantially (Figure 5).

Using the resulting coordinates from the similarity calculations and replacing the crystallized ligand with the corresponding QM optimized mebendazole's conformations, one can obtain a prediction of how mebendazole might bind to Hsp90. As seen in Figure 5, the resulting "docked" mebendazole occupies a different starting orientation within each binding pocket, and consequently forms different nonbonded contacts with different amino acids. The mebendazole's tautomers 1 and 2 have the carbamate functionality pointing out of the 2BT0 and 2WI6 binding pockets, respectively, while for 4W7T the tautomer 1 is rotated ca. $180^{\circ}$ and is deeply inserted into the pocket. These three resulting mebendazole-Hsp90 protein complexes were used as the starting structure for all-atom MD simulations.

\subsection{Mebendazole's Force-Field Validation}

Using the QM relative energies for mebendazole's tautomer 1 and 2, we can gauge how well Gaff2 performs at modeling the drug's conformational space. As seen in Table 4, Gaff2 reproduces the relative stability of the low energy conformations very well, with a maximum deviation of $-0.23 \mathrm{kcal} \cdot \mathrm{mol}^{-1}\left(\mathrm{~T}_{3}^{1} \& 4\right)$ occurring for conformations that have a relative energy of $<3.4 \mathrm{kcal} \cdot \mathrm{mol}^{-1}$. For the conformations with MP2/AVTZ relative energies between $3.4-7.4 \mathrm{kcal} \cdot \mathrm{mol}^{-1}$, Gaff2 performs less well with deviations ranging from $2.6-4.8 \mathrm{kcal} \cdot \mathrm{mol}^{-1}$. 
Table 4. Relative molecular mechanics conformational energies ${ }^{\mathrm{a}}\left(\mathrm{kcal} \cdot \mathrm{mol}^{-1}\right.$ ) for tautomers 1 and 2 , along with selected QM theory levels. Relative values are computed independently for each tautomer. (Conformation numbers are currently ordered according to the raw data - this will change. Differences are between Gaff2 and AVTZ results.)

\begin{tabular}{|c|c|c|c|c|c|c|c|}
\hline Conformation & $\begin{array}{l}\text { Tautomer } 1 \\
\text { MP2/AVTZ }\end{array}$ & Gaff2 & Diff. $^{\text {b }}$ & Conformation & $\begin{array}{l}\text { Tautomer } 2 \\
\text { MP2/AVTZ }\end{array}$ & Gaff2 & Diff. $^{b}$ \\
\hline 1,2 & 0.000 & 0.000 & 0.000 & 1,2 & 0.000 & 0.000 & 0.000 \\
\hline 3,4 & 0.443 & 0.209 & -0.234 & 3,4 & 0.272 & 0.403 & 0.131 \\
\hline 5,6 & 3.654 & 8.198 & 4.544 & 5,6 & 3.465 & 8.025 & 4.560 \\
\hline 7,8 & 4.186 & 8.577 & 4.391 & 7,8 & 3.932 & 8.766 & 4.834 \\
\hline 9,10 & 7.204 & 10.142 & 2.938 & 9,10 & 7.296 & 10.257 & 2.961 \\
\hline 11,12 & 7.559 & 10.149 & 2.590 & 11,12 & 7.450 & 10.498 & 3.048 \\
\hline 13,14 & 17.011 & 16.659 & -0.352 & 13,14 & 16.967 & 16.421 & -0.546 \\
\hline 15,16 & 17.144 & 16.659 & -0.485 & 15,16 & 17.072 & 16.421 & -0.651 \\
\hline 17,18 & 17.663 & 17.195 & -0.468 & 17,18 & 17.459 & 17.318 & -0.141 \\
\hline 19,20 & 17.779 & 17.195 & -0.584 & 19,20 & 17.535 & 17.318 & -0.217 \\
\hline Avg. of Abs. Diff. & & & 1.843 & & & & 1.899 \\
\hline Tautomer Diff. $^{\mathrm{d}}$ & 0.166 & 7.762 & & & 0.000 & 0.000 & \\
\hline
\end{tabular}

a All relative energies were computed from full optimizations performed at the specified theory levels.

b Energy difference computed between Gaff2 and MP2/AVTZ relative energies.

${ }^{c}$ Averages of the absolute differences are computed using the data show, but excludes the global minimum of each tautomer.

d The energy difference between the respective global minimum of tautomer 1 (i.e. conformations 1 and 2 ) and 2 (i.e. conformations 1 and 2).

For the highest energy conformations, Gaff2 is unable to reproduce several of the minima found by MP2/AVTZ (i.e. multiple input geometries are optimized to the same minima by Gaff2). Therefore, concerning the force field's performance in MD simulations, the low energy conformations are expected to be modelled well, while the results involving higher energy conformations would be less reliable.

\subsection{Simulations}

The similarity calculations were subsequently used to guide our choice for which protein structure and mebendazole tuatomer to use for creating our MD models. Since sampling is critical in MD simulations, we choose to use all three similarity results (Section 3.2) for creating the MD input models of mebendazole's binding to Hsp90. Consequently, six simulations were performed, which will be referred to as 2WI6-FB15, 2WI6-ff14SB, 2BT0-FB15, 2BT0-ff14SB, 4W7T-FB15 and 4W7T-ff14SB.

All simulations resulted in trajectories with stable nonbonded interactions between mebendazole and the ATP binding site. A dissociation of the ligand from the binding site was never observed during any of the 100 ns simulations. The protein structure itself was also stable, maintaining the crystals' tertiary structures. The simulations also resulted in a good general consensus of the protein's secondary structure (see Figure S6, with local deviation occurring in the residues that start and end the individual secondary elements. Consequently, all six simulations provided well-behaved and stable trajectores for further analysis into the binding of mebendazole to Hsp90.

Binding Pocket Poses Protein alignment of the individual frames within a given trajectory, followed by clustering mebendazole's position allows for the identification of its possible binding poses within the ATP binding site. From these analyses, a total of nine distinct and well populated poses were observed under physiological conditions across all simulations, as detailed in Table 5 and shown in Figure 6. Seven poses position mebendazole's terminal phenyl ring into the biding pocket with its carbamate functionality exposed to bulk water, each arising from the $2 \mathrm{WI} 6$ and $2 \mathrm{BT} 0$ simulations. The two remaning poses, arising from the $4 \mathrm{~W} 7 \mathrm{~T}$ simulations, position the carbamate into the binding pocket, with the phenyl and ketone functionality solvent exposed.

While an exact one-to-one comparison between mebendazole's QM-optimized conformations with those adopted in the MD simulations - due to the temperature effects, immersion into solution and nonbonded interaction with amino acids - can not be achieved, insights can be gained through their general comparison. 
The mebendazole conformations adopted in 2BT0-FB15 pose 0, 2BT0-FB15 pose 1 and 2BT0-ff14SB pose 1

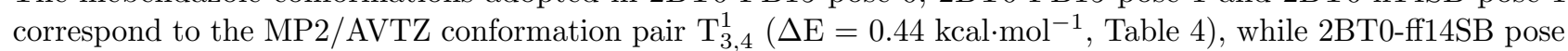
0 adopts the lower energy conformation $\mathrm{T}_{1}^{1}$. Similarly in the 2 WI6 simulations, the drug closely adopts a spatial arrangement that matches the MP2/AVTZ conformation pair $\mathrm{T}_{3}^{2}$ and $\mathrm{T}_{4}^{2}\left(\Delta \mathrm{E}=0.447 \mathrm{kcal} \cdot \mathrm{mol}^{-1}\right)$. Considering that thermal energy at body temperature is ca. $0.6 \mathrm{kcal} \cdot \mathrm{mol}^{-1}$, it is reasonable that these conformations are well populated during the MD simulations.

A different result is obtained from the $4 \mathrm{~W} 7 \mathrm{~T}$ simulations. In both resulting poses, mebendazole adopts a conformation that was not optimized by the QM calculations. These new conformations place $\mathrm{T}_{1,2}^{1}$ 's amide hydrogen aligned on the same side as the imidazole's hydrogen and in-plane with the conjugated ring. Gas-phase MM optimization of the new conformations confirms them as stationary points on GAFF2's PES, with a relative energy of $13.1 \mathrm{kcal} \cdot \mathrm{mol}^{-1}$ above the tautormer's $\mathrm{T}_{1,2}^{1}$ minima. These stabilities are within the range of similar QM amide-imidazole aligned conformations that have relative energies of ca. $17 \mathrm{kcal} \cdot \mathrm{mol}^{-1}$. Note that in these QM conformations, mebendazole's ester group is out-of-plane with the imidazole ring. Additional QM calculations were performed in order to isolate these two new conformations, but both HF/6-31G(d) and MP2/AVTZ theory levels were unable to optimized them to a stationary point on their gas-phase PESs. Consequently, these conformations are unlikely to exist for isolated mebendazole. Coupling this with the conformation's high relative energies predicted by Gaff2, if these conformations (i.e. 4W7T-FB15 pose 0 and 4W7T-ff14SB 0) exist within the ATP binding site, there must be an induced fit mechanism that includes substantial stabilization through nonbonded interactions and solvation effects.

Table 5. The nine top binding poses identified from the MD simulations. The total number of amino acids that form short-range, nonbonded interactions (i.e. within $3.4 \AA$ ) with mebendazole for at least $50 \%$ of the simulated time for each pose are provided, which are individually listed in Tables 6 and S3. Also included are the overall percentage that each pose sampled in their entire trajectory, as determined from the clustering analysis.

\begin{tabular}{cc|cc}
\hline \hline MD Model & Pose & Number of Amino Acids & Sampled (\%) \\
\hline 2WI6-FB15 & 0 & 11 & 88 \\
2WI6-ff14SB & 0 & 10 & 63 \\
& 1 & 12 & 21 \\
2BT0-FB15 & 0 & 10 & 49 \\
& 1 & 13 & 38 \\
2BT0-ff14SB & 0 & 13 & 75 \\
& 1 & 11 & 17 \\
4W7T-FB15 & 0 & 15 & 100 \\
4W7T-ff14SB & 0 & 16 & 100 \\
\hline \hline
\end{tabular}

The nine poses differ in mebendazole's relative orientations within the binding pocket, resulting in nonbonded contacts to a different set of amino acids as detailed in Tables 6 and S3. In total, 25 amino acids were identified to make stable, short-ranged nonbonded contacts with mebendazole. Of these amino acids, only 10-16 are involved for a given pose. Those that most frequently participate in binding, across all simulations, are the following residues: Asn51, Ala55, Ile96, Gly97, Met98, Asn106, Leu107, Phe138, Thr184 and Val186. Consequently, we predict that these ten amino acids are the ones most likely to be involved in binding mebendazole to the ATP binding site of Hsp90. Interestingly, 4W7T-ff14SB pose 0 is the only one that makes contacts with all of these ten amino acids.

Several Hsp90 studies have also indicated many of these amino acids as important for ligand binding, and thus lends support to the predictive nature of the MD simulations performed here. Most notably, a 2010 survey of 40 crystallized Hsp90-ligand complexes found Asn51, Ala55, Met98, Phe138 and Thr184 (plus Lys58, Asp93 and Gly97) make frequent contacts to bound ligands [28]. A recent pharmacophore model identified Ala55, Lys58, Asp93, Ile96, Met98 and Thr184 as important in binding Hsp90 inhibitors [37]. Of the MD predicted poses, 2Bt0-ff14SB pose 0 and 2Bt0-FB15 pose 1 form interactions with all 6 of the pharmacophore's amino acids (Table S3).

A comparison of binding pocket topology can be achieved by selectively mapping different colors to the amino acids categorized by the a) pharmacophore [37], b) most frequently (Table 6) and c) least frequently (Table S3) involved mebendazole binders that were identified from the MD simulations. As seen in Figure 6, the binding site amino acid composition and their positions differ significantly across the nine poses, arising primarily from the spacial placement of amino acids' side chains. Generally consistent across the poses are the positions of pharmacophore amino acids (red) that are deep in the binding pocket, and the most frequent (cyan) amino 


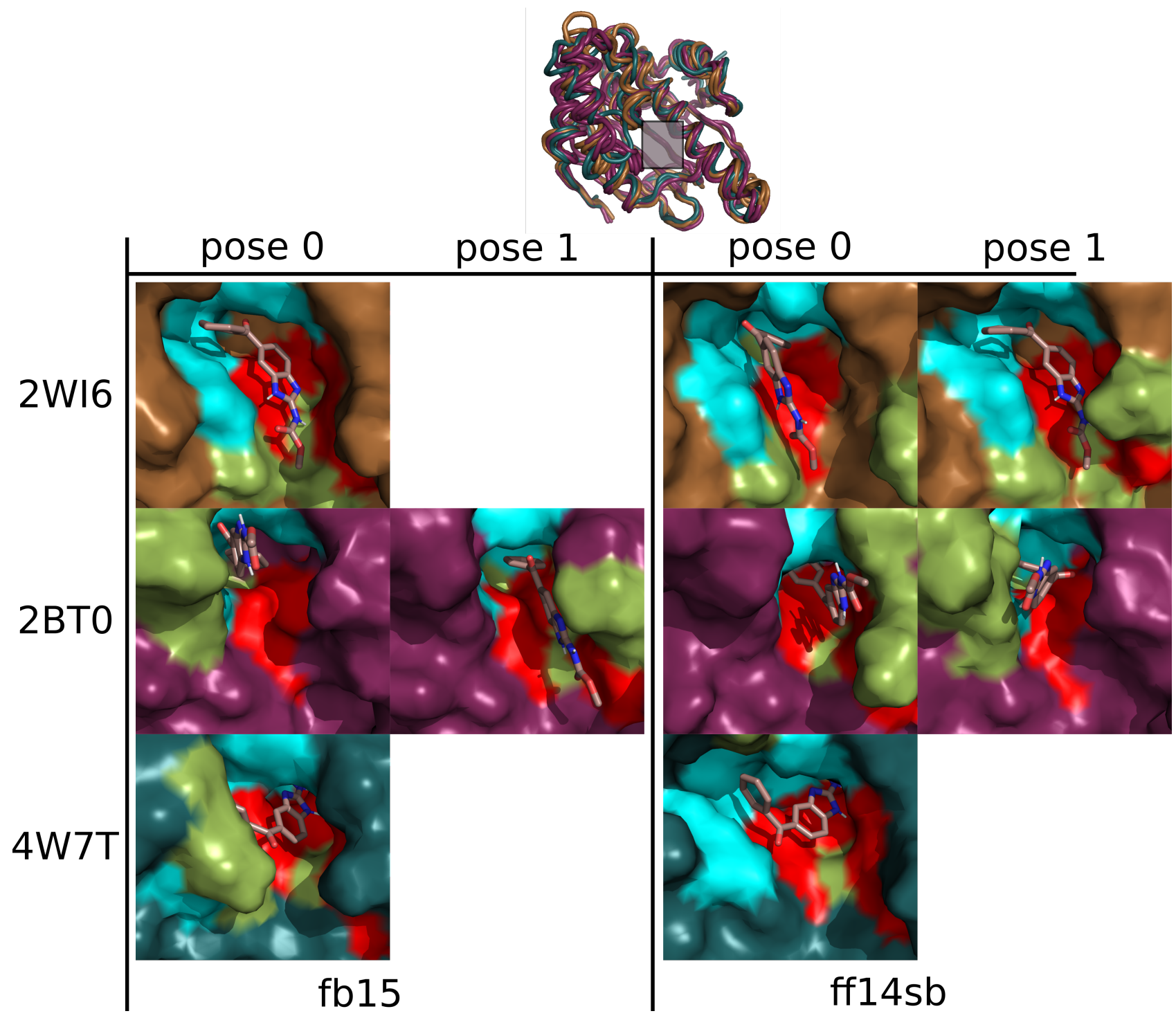

Figure 6: The major binding poses predicted by molecular dynamics simulations. All images were created by aligning the proteins, allowing for a consistent orientation of the binding site. The 2WI6 (blue-green) and 2BT0 (purple) structures are the best representative of the centroid identified in the cluster analysis, while those for 4W7T (orange) represent structure with the lowest RMSD value to the average structure from their respective 100 ns trajectories. The pharmacophore (red [37]), most frequent (cyan, Table 6), and less frequent (olive green, Table S3) amino acids are highlighted if indicated they fall within $3.4 \AA$ of mebendazole in a given pose. Note that if a residue is categorized as both a pharmacophore and either as most/least frequent amino acid, then it is colored red. 
Table 6. The percentage of time for the most frequently involved amino acids that form short-range, nonbonded interactions (i.e. $\leq 3.4 \AA$ ) with mebendazole. The percentages are computed for the trajectory portion that corresponds to each identified binding mode. The values in parentheses are the binding pose populations computed in the last $100 \mathrm{~ns}$. All interactions that occur for over $50 \%$ for a given pose are reported.

\begin{tabular}{lc|cccccccccc}
\hline \hline MD Model & Pose & Asn51 & Ala55 & Ile96 & Gly97 & Met98 & Asn106 & Leu107 & Phe138 & Thr184 & Val186 \\
\hline 2WI6-FB15 & 0 & 99.7 & 98.0 & 100.0 & 99.2 & 100.0 & 99.9 & 99.9 & 99.8 & 94.2 & \\
2WI6-ff14SB & 0 & 94.0 & & & & 99.9 & 95.8 & 99.9 & 99.9 & 96.4 & 91.7 \\
& 1 & 99.8 & 98.6 & 98.9 & 97.7 & 99.9 & 99.2 & 99.8 & 97.8 & 84.8 & \\
2BT0-FB15 & 0 & 99.9 & & & & 97.4 & & 99.9 & 99.7 & 91.8 & 99.0 \\
& 1 & 99.9 & 95.9 & 99.8 & 98.8 & 100.0 & & 79.6 & 76.8 & 98.6 \\
2BT0-ff14SB & 0 & 99.9 & 100.0 & 99.5 & 89.5 & 100.0 & & 81.5 & 69.4 & 100.0 & 85.9 \\
& 1 & 99.1 & 55.0 & & & 98.1 & & 100.0 & 97.7 & 87.5 & 80.3 \\
4W7T-FB15 & 0 & 97.1 & 99.9 & 77.2 & 84.8 & 100.0 & 91.0 & 94.3 & & 100.0 & 99.8 \\
4W7T-ff14SB & 0 & 98.6 & 99.6 & 60.1 & 50.9 & 98.9 & 86.5 & 96.9 & 74.3 & 100.0 & 99.9 \\
\hline \hline
\end{tabular}

acids forming the top and left-side of the binding pocket. The shape and composition of the binding pockets' entrance varies significantly across the poses, best exemplified by the differences in the less frequent (olive green) interacting amino acids. Thus, taken together and assuming that the poses sampled by the different MD models are meaningful, the binding site is dynamically labile, which is supported by the large number of Hsp90-ligand crystal structures deposited in the Protein Data Bank [79].

To further investigate the protein's flexibility, an analysis of the RMSF of the amino acids' backbone atoms (ie. $\mathrm{C}, \mathrm{C}_{\alpha}$ and $\mathrm{N}$ ) were performed. As shown in Figure 7, the fluctuations across all six MD models show very similar patterns, with differences mainly seen in the RMSF's magnitude. The majority of the binding pocket amino acids reside in the more dynamically stable regions of the protein fold. These observations supports the above conclusion that the changes seen within the binding pocket topology are largely due to the local amino acid side chain motion.

The protein residues with the largest fluctuations occur in helices and loops that are not directly involved in mebendazole's binding, while the $\beta$-sheets provide local regions of dynamic stability (Figure 7 ). Interestingly, the "lid" region (i.e. Gly108-Tyr139) displays significant fluctuations, indicating that it is dynamically labile as suggested by the open and closed state seen in crystallography [110-112]. However, at the timescales studied herein, and in the absence of a second Hsp90, the large-scale movement to a lid-closed state is not observed. The fluctuation observed herein are consistent with other recently reported long (200 and $100 \mathrm{~ns}$ ) MD simulation of Hsp90-ligand complexes [25,38].

Insight into the role that water has in mebendazole's binding can be gained through an SDF analysis of the first solvation shell of the drug (see Figures S4-S5). As seen in Table 7, the binding poses predicted by both 4W7T simulations - which position mebendazole's phenyl groups near the binding pocket's entrance - have the least waters (i.e. 12 molecules) forming the durg's first solvation shell. This is followed by the 2WI6-FB15 trajectory, with 15 waters solvating mebendazole. The remaining trajectories provide poses that are notably more solvated, with 19-22 water composing the first solvation shell.

Table 7. The average number of waters that are within $3.4 \AA$ of mebendazole for each MD simulation.

\begin{tabular}{lccc}
\hline \hline & 2WI6 & 2BT0 & 4W7T \\
FB15 & $15.2 \pm 2.5$ & $22.2 \pm 4.8$ & $12.1 \pm 2.0$ \\
ff14SB & $21.0 \pm 4.2$ & $19.4 \pm 3.1$ & $12.1 \pm 2.2$ \\
\hline \hline
\end{tabular}

A majority of the waters interact with mebendazole where it is exposed to bulk solvent, or in the space formed between the drug and a single side of the binding pocket. Most of the water molecules translates fairly uninhibited, creating a large globular and continuous spacial occupancy, as exemplified in Figure 8. Consequently, it is difficult to isolate specific waters within these globular regions that unequivocally bridge an individual amino acid and mebendazole. Apart from these globular density regions, there are localized areas where 1-2 waters do form isolated and well resolved occupancy densities. The most frequently observed bridging water occurs with Asn51, occurring in seven of the poses (i.e. absent in the 2WI6-ff14SB simulation). Other bridging waters that were observed in 1-2 poses involved the amino acids Asp54, Asp93, Asp102, Ans106, Lys112 and Thr184. For the remaining instances, water molecules form a bridge between amino acids and do not form 


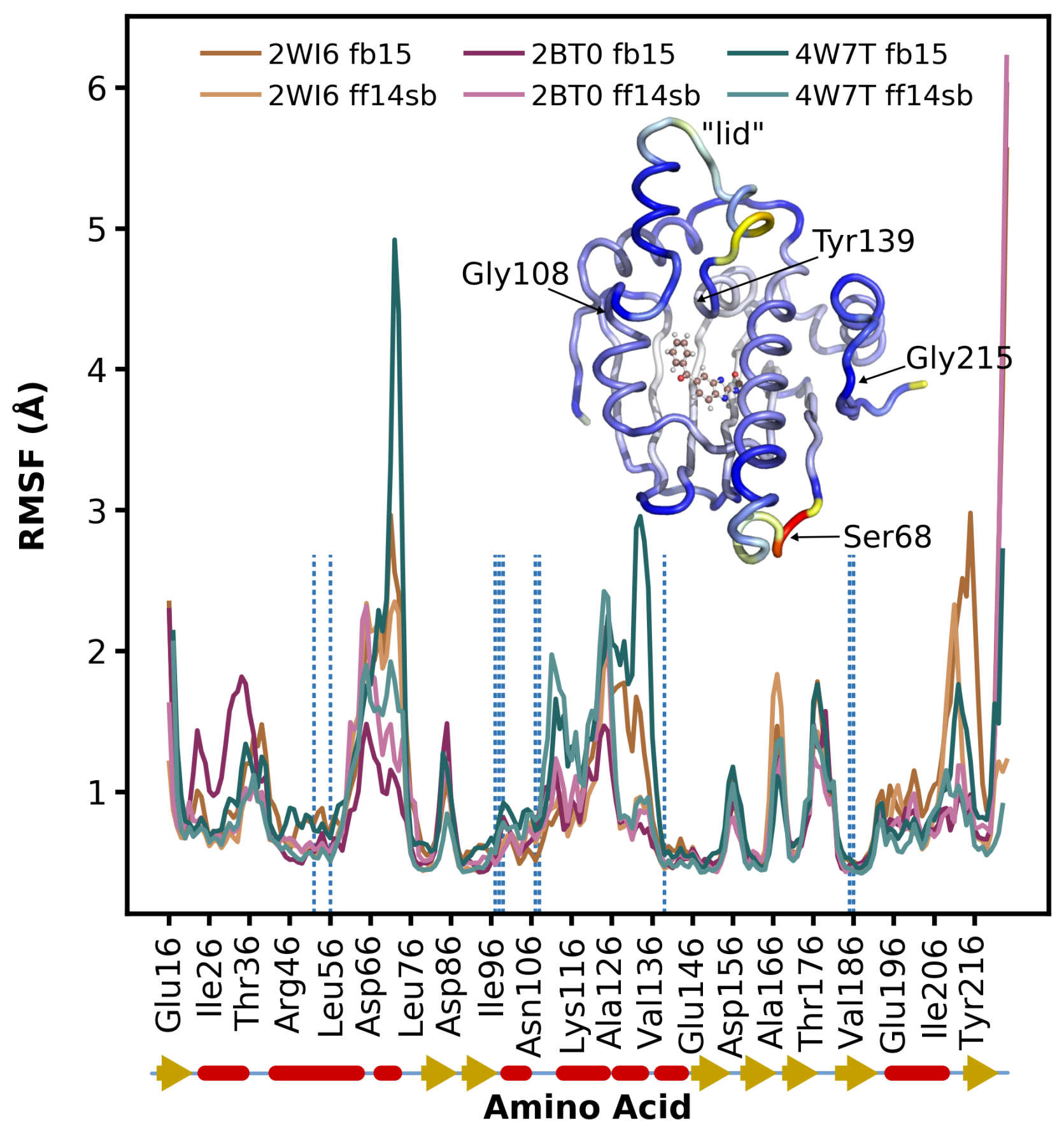

Figure 7: The root-mean-square fluctuations $(\AA)$ for the most populated binding poses predicted by molecular dynamics simulations. The dash lines indicate the 10 binding pocket amino acids that most often form the close nonbonded interactions with mebendazole (see Table 6). To represent where the generally low (blue) and high (red) fluctuations occur, 4W7T-FB15 pose 0's fluctuations are mapped onto the representative structure; the magnitude at Ser68 and Gly69 was reduced to $3.5 \AA$ to allow for the lid fluctuations to be seen better. The secondary structure representation is estimated from the DSSP calculation across all trajectories (see Figure S6) 
notable interaction with mebendazole.

Table 8. MM/PBSA relative binding energies $\left(\Delta E_{\text {bind }}\right)$ of the different poses that mebendazole adopts within the ATP binding pocket of Hsp90.

\begin{tabular}{l|cc|cc}
\hline \hline & \multicolumn{2}{|c|}{ FB15 } & \multicolumn{2}{c}{ ff14SB } \\
& Pose 0 & Pose 1 & Pose 0 & Pose 1 \\
\hline 2WI6 & $8.9 \pm 4.0$ & & $6.2 \pm 3.9$ & $12.6 \pm 4.5$ \\
2BT0 & $0.3 \pm 3.4$ & $9.2 \pm 3.8$ & $4.6 \pm 3.9$ & $8.0 \pm 4.0$ \\
4W7T & $0.0 \pm 4.7$ & & $6.3 \pm 5.1$ & \\
\hline \hline
\end{tabular}

In an attempt to provide a ranking of the poses, MM/PBSA binding energies $\left(\Delta E_{\mathrm{bind}}\right)$ were computed. Here, we are interested only in the relative trends provided by the MM/PBSA calculations, and do not expect that the absolute computed energies reflect those that could be obtained experimentally. As seen in Table 8 , when two poses are identified for a given protein model, the most populated pose (i.e. pose 0) has the more favorable binding energy. Thus, providing some confidence that the computed trends are reliable. Of the poses predicted, 2BT0-FB15 pose 0 and $4 \mathrm{~W} 7 \mathrm{~T}-\mathrm{FB} 15$ pose 0 have the lowest binding energies, both falling within the standard deviation of one another. If one disregards the solvation contribution, and only consider the interaction energy arising from nonbonded interactions (i.e. Lennard-Jones and electrostatics forces), both 4W7T-FB15 poses provide the most favorable interactions (pose $0=-81 \mathrm{kcal} \cdot \mathrm{mol}^{-1}$; pose $1=-70 \mathrm{kcal} \cdot \mathrm{mol}^{-1}$ ), followed by 2WI6-FB15 pose $0\left(-54 \mathrm{kcal} \cdot \mathrm{mol}^{-1}\right)$ and $2 \mathrm{WI} 6$-ff14SB pose $1\left(52 \mathrm{kcal} \cdot \mathrm{mol}^{-1}\right)$. Consequently, both energetic analyses, with and without solvation effects, reveal that $4 \mathrm{~W} 7 \mathrm{~T}-\mathrm{FB} 15$ pose 0 is the most favorable.

Thus, 4W7T-FB15 pose 0 appears to be a good candidate for the pose that could be resolved experimentally through crystallography. This pose make close contact between mebendazole and 15 amino acids, with nine out of the ten most frequently involved amino acids being included in the binding. Only 4W7T-ff14SB pose 0 has more, with one additional amino acids that interact with mebendazole. However, some uncertainty exists in this prediction because the mebendazole conformation that is present does not exist on the gas-phase MP2/AVTZ PES.

\section{Conclusions}

An extensive search of mebendazole conformational space, across all five tautomer forms, was performed in the gas phase using the MP2/AVTZ theory level. A total of 152 conformations were identified as stationary points on the molecule's PES. The most stable conformations coincide with the known crystal structures. Similarity calculations computed between the eight most stable mebendazole conformational predicted by QM to 300 crystallized ligands bound to Hsp90 revealed three possible poses that mebendazole could adopt within the ATP binding site. Using the results of the similarity calculations, six MD models were generated that differ by the choice of protein crystal used and in the force field employed for modeling the protein.

Clustering the resulting MD trajectories lead to nine possible binding poses. Trajectory analyses of the drug's nonbonded interactions with the Hsp90 predict that Asn51, Ala55, Ile96, Gly97, Met98, Asn106, Leu107, Phe138, Thr184 and Val186 are most likely to be involved in stabilizing the binding complex. The protein backbone atoms that comprise the ATP binding pocket has a high degree of dynamic stability in the presence of mebendazole, with the largest backbone fluctuations occurring away from the binding pocket at Ser68 and in the lid region.

The MD simulations presented here indicate that mebendazole can adopt several dynamically stable poses within the ATP binding pocket of Hsp90. Based on MM/PBSA calculations, 4W7T-FB15 pose 0 is predicted to be the most experimentally relevant binding pose. However, this conformation adopted by mebendazole in this pose and that of 4 W7T-ff14SB pose 0 does not exist on the gas-phase MP2/AVTZ PES. Consequently, these poses are either artifacts arising from the molecular mechanics' force field, or there is an induced fit mechanics that occurs during mebendazole binding to the ATP pocket. Aside from these two poses, the conformations adopted by mebendazole exist on the MP2/AVTZ PES, giving us confidence that one or more of the poses predicted here are physiologically and experimentally relevant. This supports the use of mebendazole as a future therapeutic option as an Hsp90 inhibitor for the treatment of diverse cancers and as a potential new therapeutic strategy to limit the ability of cancer cells to adapt and evolve drug resistance. 


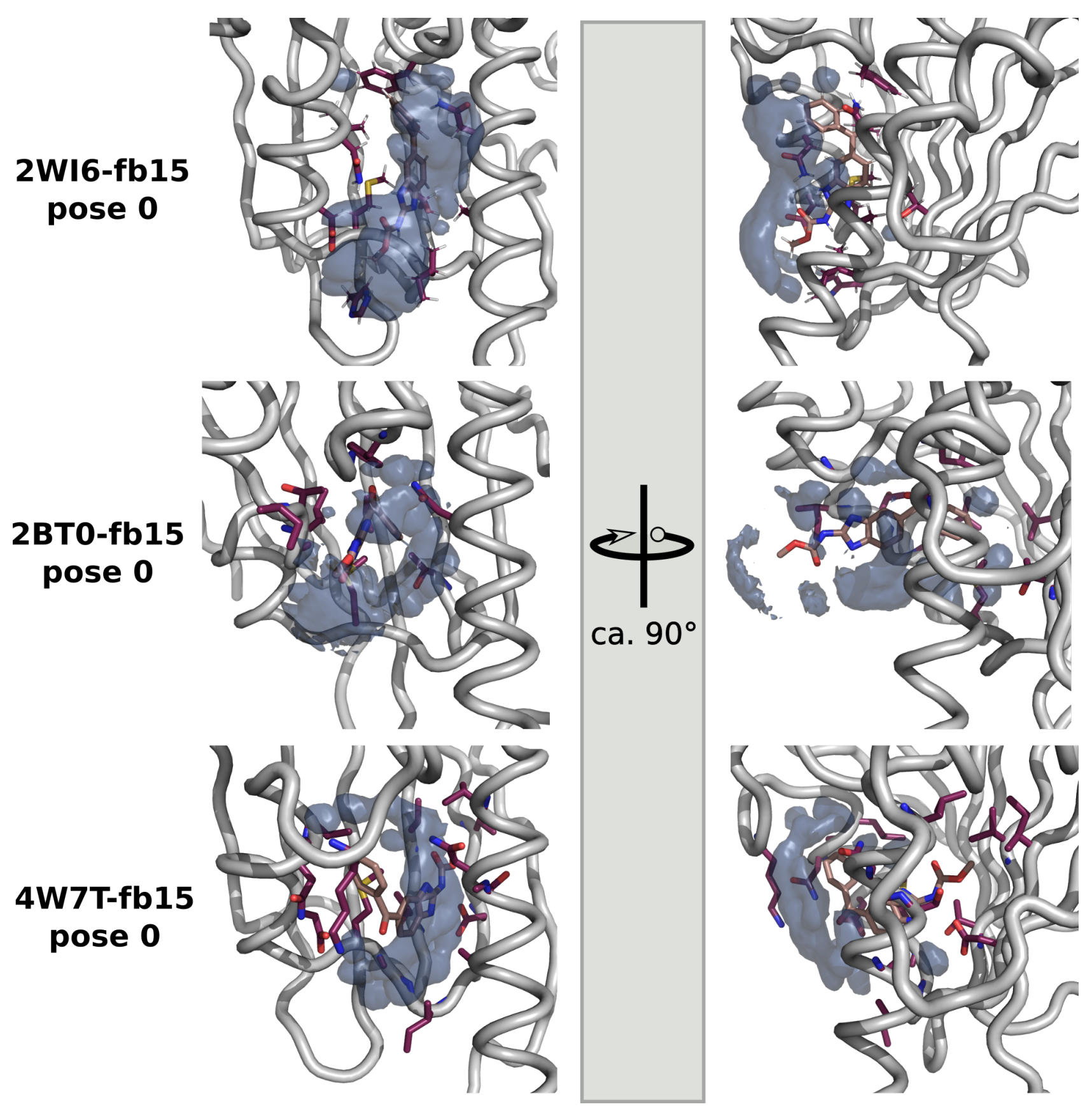

Figure 8: The spatial distribution of mebendazole's first solvation shell (blue isosurface) for the primary poses computed from the FB15 force field. Two orientations are shown in each case, and the isosurface encapsulates a normalized occupancy density (molecule $/ \AA^{3}$ ) of $80 \%$. 


\section{Acknowledgments}

We would also like to thank Rudolf Berrendorf and Javed Razzaq for their continuous development and support of the Hochschule Bonn-Rhein-Sieg's computing cluster. The UBRS's computer hardware was supported by the Federal Ministry for Education and Research and by the Ministry for Innovation, Science, Research, and Technology of the state Northrhine-Westfalia (research grant 13FH156IN6). We would like to thank the Erich und Gertrud Roggenbuck-Stiftung for their financial support that allowed us to conduct this study.

\section{Conflicts of Interests}

WF has an advisory and consulting role for Amgen; an advisory role for ARIAD/Incyte, Novartis, Pfizer; Celgene, Morphosys, AbbVie, Jazz Pharmaceuticals, and Servier; receives royalties from Amgen; receives support for meeting attendance from Amgen, Gilead, Servier, Jazz Pharmaceuticals, and Daiichi Sankyo; and research funding from Amgen and Pfizer.

\section{References}

\section{References}

[1] S. E. Jackson, Hsp90: Structure and Function, pp. 155-240. Berlin, Heidelberg: Springer Berlin Heidelberg, 2013.

[2] M. Taipale, D. F. Jarosz, and S. Lindquist, "Hsp90 at the hub of protein homeostasis: emerging mechanistic insights," Nature Reviews Molecular Cell Biology, vol. 11, no. 7, pp. 515-528, 2010.

[3] J. C. Young, I. Moarefi, and F. U. Hartl, "Hsp90: a specialized but essential protein-folding tool," The Journal of cell biology, vol. 154, pp. 267-273, July 2001.

[4] R. Yuan, X. Zhu, G. Wang, S. Li, and P. Ao, "Cancer as robust intrinsic state shaped by evolution: a key issues review.," Reports on progress in physics. Physical Society (Great Britain), vol. 80, p. 042701, Apr 2017.

[5] L. Whitesell and N. U. Lin, "Hsp90 as a platform for the assembly of more effective cancer chemotherapy.," Biochimica et biophysica acta, vol. 1823, pp. 756-66, Mar 2012.

[6] M. P. Goetz, D. O. Toft, M. M. Ames, and C. Erlichman, "The Hsp90 chaperone complex as a novel target for cancer therapy," Annals of Oncology, vol. 14, no. 8, pp. 1169-1176, 2003.

[7] J. Travers, S. Sharp, and P. Workman, "HSP90 inhibition: two-pronged exploitation of cancer dependencies," Drug Discovery Today, vol. 17, no. 5, pp. 242-252, 2012. Special Issue on Cancer Development.

[8] G. D. Lianos, G. A. Alexiou, A. Mangano, A. Mangano, S. Rausei, L. Boni, G. Dionigi, and D. H. Roukos, "The role of heat shock proteins in cancer," Cancer Letters, vol. 360, no. 2, pp. 114-118, 2015.

[9] L. M. Butler, R. Ferraldeschi, H. K. Armstrong, M. M. Centenera, and P. Workman, "Maximizing the therapeutic potential of HSP90 inhibitors," Molecular Cancer Research, vol. 13, no. 11, pp. 1445-1451, 2015.

[10] G. A. Alexiou, G. Vartholomatos, K. Stefanaki, A. Patereli, L. Dova, A. Karamoutsios, G. Lallas, G. Sfakianos, M. Moschovi, and N. Prodromou, "Expression of heat shock proteins in medulloblastoma," Journal of Neurosurgery: Pediatrics PED, vol. 12, no. 5, pp. 452-457, 2013.

[11] F. Zagouri, T. Sergentanis, A. Nonni, C. Papadimitriou, A. Pazaiti, N. V. Michalopoulos, P. Safioleas, A. Lazaris, G. Theodoropoulos, E. Patsouris, and G. Zografos, "Decreased Hsp90 expression in infiltrative lobular carcinoma: an immunohistochemical study," BMC Cancer, vol. 10, no. 1, p. 409, 2010.

[12] S. Sharp and P. Workman, "Inhibitors of the HSP90 molecular chaperone: Current status," vol. 95 of Advances in Cancer Research, pp. 323-348, Academic Press, 2006.

[13] P. A. Brough, X. Barril, J. Borgognoni, P. Chene, N. G. M. Davies, B. Davis, M. J. Drysdale, B. Dymock, S. A. Eccles, C. Garcia-Echeverria, C. Fromont, A. Hayes, R. E. Hubbard, A. M. Jordan, M. R. Jensen, A. Massey, A. Merrett, A. Padfield, R. Parsons, T. Radimerski, F. I. Raynaud, A. Robertson, S. D. Roughley, J. Schoepfer, H. Simmonite, S. Y. Sharp, A. Surgenor, M. Valenti, S. Walls, P. Webb, M. Wood, 
P. Workman, and L. Wright, "Combining hit identification strategies: Fragment-based and in silico approaches to orally active 2-aminothieno[2,3-d]pyrimidine inhibitors of the Hsp90 molecular chaperone," Journal of Medicinal Chemistry, vol. 52, no. 15, pp. 4794-4809, 2009.

[14] G. P. Nagaraju, T.-E. Long, W. Park, J. C. Landry, L. Taliaferro-Smith, A. B. Farris, R. Diaz, and B. F. El-Rayes, "Heat shock protein 90 promotes epithelial to mesenchymal transition, invasion, and migration in colorectal cancer," Molecular Carcinogenesis, vol. 54, no. 10, pp. 1147-1158, 2015.

[15] T. Uno, Y. Kawai, S. Yamashita, H. Oshiumi, C. Yoshimura, T. Mizutani, T. Suzuki, K. T. Chong, K. Shigeno, M. Ohkubo, Y. Kodama, H. Muraoka, K. Funabashi, K. Takahashi, S. Ohkubo, and M. Kitade, "Discovery of 3-ethyl-4-(3-isopropyl-4-(4-(1-methyl-1h-pyrazol-4-yl)-1h-imidazol-1-yl)-1h-pyrazolo[3,4b]pyridin-1-yl)benzamide (TAS-116) as a potent, selective, and orally available HSP90 inhibitor," J. Med. Chem., vol. 62, no. 2, pp. 531-551, 2018.

[16] P. T. Harrison and P. H. Huang, "Exploiting vulnerabilities in cancer signalling networks to combat targeted therapy resistance.," Essays in biochemistry, vol. 62, pp. 583-593, Oct 2018.

[17] A. M. Jaeger and L. Whitesell, "Hsp90: Enabler of cancer adaptation," Annu. Rev. Cancer Biol., vol. 3, pp. 275-297, Mar. 2019.

[18] C. Prodromou, S. Roe, R. O'Brien, J. E. Ladbury, P. W. Piper, and L. H. Pearl, "Identification and structural characterization of the ATP/ADP-binding site in the Hsp90 molecular chaperone," Cell, vol. 90, no. 1, pp. 65-75, 1997.

[19] J. M. Jez, J. C.-H. Chen, G. Rastelli, R. M. Stroud, and D. V. Santi, "Crystal structure and molecular modeling of 17-DMAG in complex with human Hsp90," Chemistry \& Biology, vol. 10, no. 4, pp. 361-368, 2003.

[20] G. Colombo, G. Morra, M. Meli, and G. Verkhivker, "Understanding ligand-based modulation of the Hsp90 molecular chaperone dynamics at atomic resolution," Proceedings of the National Academy of Sciences, vol. 105, no. 23, pp. 7976-7981, 2008.

[21] A. Lauria, M. Ippolito, and A. M. Almerico, "Inside the Hsp90 inhibitors binding mode through induced fit docking," Journal of Molecular Graphics and Modelling, vol. 27, no. 6, pp. 712-722, 2009.

[22] G. Morra, G. Verkhivker, and G. Colombo, "Modeling signal propagation mechanisms and ligand-based conformational dynamics of the Hsp90 molecular chaperone full-length dimer," PLOS Computational Biology, vol. 5, no. 3, pp. 1-16, 2009.

[23] J. Liu, F. Wang, Z. Ma, X. Wang, and Y. Wang, "Structural determination of three different series of compounds as Hsp90 inhibitors using 3D-QSAR modeling, molecular docking and molecular dynamics methods," International Journal of Molecular Sciences, vol. 12, no. 2, pp. 946-970, 2011.

[24] K. Kawaguchi, H. Saito, S. Okazaki, and H. Nagao, "Molecular dynamics study on the free energy profile for dissociation of ADP from N-terminal domain of Hsp90," Chemical Physics Letters, vol. 588, pp. 226-230, 2013.

[25] A. Nazar, G. Abbas, and S. S. Azam, "Deciphering the inhibition mechanism of under trial Hsp90 inhibitors and their analogues: A comparative molecular dynamics simulation," Journal of Chemical Information and Modeling, vol. 60, no. 8, pp. 3812-3830, 2020.

[26] F. Yan, X. Liu, S. Zhang, Q. Zhang, and J. Chen, "Understanding conformational diversity of heat shock protein 90 (HSP90) and binding features of inhibitors to HSP90 via molecular dynamics simulations," Chemical Biology \& Drug Design, vol. 95, no. 1, pp. 87-103, 2020.

[27] T.-J. Hong, H. Park, Y.-J. Kim, J.-H. Jeong, and J.-S. Hahn, "Identification of new hsp90 inhibitors by structure-based virtual screening," Bioorganic $\&$ Medicinal Chemistry Letters, vol. 19, no. 16, pp. 4839-4842, 2009.

[28] S. Sakkiah, S. Thangapandian, S. John, Y. J. Kwon, and K. W. Lee, "3D QSAR pharmacophore based virtual screening and molecular docking for identification of potential HSP90 inhibitors," European Journal of Medicinal Chemistry, vol. 45, no. 6, pp. 2132-2140, 2010.

[29] S. Saxena, S. Chaudhaery, K. Varshney, and A. Saxena, "Pharmacophore-based virtual screening and docking studies on Hsp90 inhibitors," SAR and QSAR in Environmental Research, vol. 21, no. 5-6, pp. 445-462, 2010. 
[30] S. Verma, A. Singh, and A. Mishra, "Dual inhibition of chaperoning process by taxifolin: Molecular dynamics simulation study," Journal of Molecular Graphics and Modelling, vol. 37, pp. 27-38, 2012.

[31] S. D. Gupta, D. Snigdha, G. I. Mazaira, M. D. Galigniana, C. Subrahmanyam, N. Gowrishankar, and N. Raghavendra, "Molecular docking study, synthesis and biological evaluation of schiff bases as Hsp90 inhibitors," Biomedicine \& Pharmacotherapy, vol. 68, no. 3, pp. 369-376, 2014.

[32] M. Abbasi, H. Sadeghi-Aliabadi, F. Hassanzadeh, and M. Amanlou, "Prediction of dual agents as an activator of mutant p53 and inhibitor of Hsp90 by docking, molecular dynamic simulation and virtual screening," Journal of Molecular Graphics and Modelling, vol. 61, pp. 186-195, 2015.

[33] R. D. Teo, S. S. Dong, Z. Gross, H. B. Gray, and W. A. Goddard, "Computational predictions of corroles as a class of Hsp90 inhibitors," Mol. BioSyst., vol. 11, pp. 2907-2914, 2015.

[34] S. T. Baby, S. Sharma, S. Enaganti, and P. R. Cherian, "Molecular docking and pharmacophore studies of heterocyclic compounds as heat shock protein 90 (Hsp90) inhibitors," Bioinformation, vol. 12, no. 28232775, pp. 149-155, 2016.

[35] M. Abbasi, H. Sadeghi-Aliabadi, and M. Amanlou, "3D-QSAR, molecular docking, and molecular dynamic simulations for prediction of new Hsp90 inhibitors based on isoxazole scaffold," Journal of Biomolecular Structure and Dynamics, vol. 36, no. 6, pp. 1463-1478, 2018.

[36] I. D'Annessa, S. Raniolo, V. Limongelli, D. Di Marino, and G. Colombo, "Ligand binding, unbinding, and allosteric effects: Deciphering small-molecule modulation of HSP90," Journal of Chemical Theory and Computation, vol. 15, no. 11, pp. 6368-6381, 2019.

[37] S. Rampogu, S. Parate, S. Parameswaran, C. Park, A. Baek, M. Son, Y. Park, S. J. Park, and K. W. Lee, "Natural compounds as potential Hsp90 inhibitors for breast cancer-pharmacophore guided molecular modelling studies," Computational Biology and Chemistry, vol. 83, p. 107113, 2019.

[38] M. Abbasi, M. Amanlou, M. Aghaei, M. Bakherad, R. Doosti, and H. Sadeghi-Aliabadi, "New heat shock protein (Hsp90) inhibitors, designed by pharmacophore modeling and virtual screening: synthesis, biological evaluation and molecular dynamics studies," Journal of Biomolecular Structure and Dynamics, vol. 38, no. 12, pp. 3462-3473, 2020.

[39] S. Gathiaka, S. Liu, M. Chiu, H. Yang, J. A. Stuckey, Y. N. Kang, J. Delproposto, G. Kubish, J. B. Dunbar, H. A. Carlson, S. K. Burley, W. P. Walters, R. E. Amaro, V. A. Feher, and M. K. Gilson, "D3R grand challenge 2015: Evaluation of protein-ligand pose and affinity predictions," Journal of Computer-Aided Molecular Design, vol. 30, no. 9, pp. 651-668, 2016.

[40] N. Deng, W. F. Flynn, J. Xia, R. S. K. Vijayan, B. Zhang, P. He, A. Mentes, E. Gallicchio, and R. M. Levy, "Large scale free energy calculations for blind predictions of protein-ligand binding: the D3R grand challenge 2015," Journal of Computer-Aided Molecular Design, vol. 30, no. 9, pp. 743-751, 2016.

[41] A. S. Mey, J. Juárez-Jiménez, A. Hennessy, and J. Michel, "Blinded predictions of binding modes and energies of HSP90- $\alpha$ ligands for the 2015 D3R grand challenge," Bioorganic $\&$ Medicinal Chemistry, vol. 24, no. 20, pp. 4890-4899, 2016. Advances in Computational and Medicinal Chemistry.

[42] M. Misini Ignjatović, O. Caldararu, G. Dong, C. Muñoz-Gutierrez, F. Adasme-Carreño, and U. Ryde, "Binding-affinity predictions of HSP90 in the D3R grand challenge 2015 with docking, MM/GBSA, QM/MM, and free-energy simulations," Journal of Computer-Aided Molecular Design, vol. 30, no. 9, pp. 707-730, 2016.

[43] E. Selwa, V. Y. Martiny, and B. I. Iorga, "Molecular docking performance evaluated on the D3R grand challenge 2015 drug-like ligand datasets," Journal of Computer-Aided Molecular Design, vol. 30, no. 9, pp. 829-839, 2016.

[44] I. Slynko, F. Da Silva, G. Bret, and D. Rognan, "Docking pose selection by interaction pattern graph similarity: application to the D3R grand challenge 2015," Journal of Computer-Aided Molecular Design, vol. 30, no. 9, pp. 669-683, 2016.

[45] Z. Ye, M. P. Baumgartner, B. M. Wingert, and C. J. Camacho, "Optimal strategies for virtual screening of induced-fit and flexible target in the 2015 D3R grand challenge," Journal of Computer-Aided Molecular Design, vol. 30, no. 9, pp. 695-706, 2016. 
[46] X. Xu, C. Yan, and X. Zou, "Improving binding mode and binding affinity predictions of docking by ligand-based search of protein conformations: evaluation in D3R grand challenge 2015," Journal of Computer-Aided Molecular Design, vol. 31, no. 8, pp. 689-699, 2017.

[47] T. Mukhopadhyay, J.-i. Sasaki, R. Ramesh, and J. A. Roth, "Mebendazole elicits a potent antitumor effect on human cancer cell lines both in vitro and in vivo," Clinical Cancer Research, vol. 8, no. 9, pp. 2963-2969, 2002 .

[48] J.-i. Sasaki, R. Ramesh, S. Chada, Y. Gomyo, J. A. Roth, and T. Mukhopadhyay, "The anthelmintic drug mebendazole induces mitotic arrest and apoptosis by depolymerizing tubulin in non-small cell lung cancer cells," Molecular Cancer Therapeutics, vol. 1, no. 13, pp. 1201-1209, 2002.

[49] D. Martarelli, P. Pompei, C. Baldi, and G. Mazzoni, "Mebendazole inhibits growth of human adrenocortical carcinoma cell lines implanted in nude mice," Cancer Chemotherapy and Pharmacology, vol. 61, no. 5, pp. 809-817, 2008.

[50] M. De Witt, A. Gamble, D. Hanson, D. Markowitz, C. Powell, S. Al Dimassi, M. Atlas, J. Boockvar, R. Ruggieri, and M. Symons, "Repurposing mebendazole as a replacement for vincristine for the treatment of brain tumors," Molecular Medicine, vol. 23, no. 1, pp. 50-56, 2017.

[51] C. M. Simbulan-Rosenthal, S. Dakshanamurthy, A. Gaur, Y.-S. Chen, H.-B. Fang, M. Abdussamad, H. Zhou, J. Zapas, V. Calvert, E. F. Petricoin, M. B. Atkins, S. W. Byers, and D. S. Rosenthal, "The repurposed anthelmintic mebendazole in combination with trametinib suppresses refractory NRAS ${ }^{261 K}$ melanoma," Oncotarget, vol. 8, no. 8, 2017.

[52] A. E. Guerini, L. Triggiani, M. Maddalo, M. L. Bonú, F. Frassine, A. Baiguini, A. Alghisi, D. Tomasini, P. Borghetti, N. Pasinetti, R. Bresciani, S. M. Magrini, and M. Buglione, "Mebendazole as a candidate for drug repurposing in oncology: An extensive review of current literature," Cancers, vol. 11, p. $1284,2019$.

[53] X. Wang, K. Lou, X. Song, H. Ma, X. Zhou, H. Xu, and W. Wang, "Mebendazole is a potent inhibitor to chemoresistant T cell acute lymphoblastic leukemia cells," Toxicology and Applied Pharmacology, vol. 396, p. 115001, 2020.

[54] V. Walf-Vorderwülbecke, K. Pearce, T. Brooks, M. Hubank, M. M. van den Heuvel-Eibrink, C. M. Zwaan, S. Adams, D. Edwards, J. Bartram, S. Samarasinghe, P. Ancliff, A. Khwaja, N. Goulden, G. Williams, J. de Boer, and O. Williams, "Targeting acute myeloid leukemia by drug-induced c-MYB degradation," Leukemia, vol. 32, no. 4, pp. 882-889, 2018.

[55] A. V. Wojcicki, M. Kadapakkam, A. Frymoyer, N. Lacayo, H.-D. Chae, and K. M. Sakamoto, "Repurposing drugs for acute myeloid leukemia: A worthy cause or a futile pursuit?," Cancers, vol. 12, no. 2, p. 441, 2020.

[56] F. Freisleben, F. Modemann, K. N. Kirschner, J. Muschhammer, H. Stamm, F. Brauneck, A. Krispien, C. Bokemeyer, J. Wellbrock, and M. Walter Fiedler, "Mebendazole mediates proteasomal degradation of GLI transcription factors in acute myeloid leukemia in a preclinical and clinical setting," Clinical Cancer Research, p. manuscript in preparation, 2021.

[57] A. Dayan, "Albendazole, mebendazole and praziquantel. review of non-clinical toxicity and pharmacokinetics," Acta Tropica, vol. 86, no. 2, pp. 141-159, 2003.

[58] W. H. Organization, "World health organization model list of essential medicines: 21st list 2019," technical documents, 2019.

[59] Y. Gao, J. Wang, C.-F. Zhang, X.-H. Xu, M. Zhang, and L.-Y. Kong, "CCDC 940012: Experimental crystal structure determination," 2014.

[60] N. M. Blaton, O. M. Peeters, and C. J. De Ranter, "(5-benzoyl-1h-benzimidazol-2-yl)-carbamic acid methyl-ester hydrobromide (mebendazole. hbr), C16H14BrN3O3," Crystal Structure Communications, vol. 9, no. 1, pp. 181-186, 1980 .

[61] M. R. Caira, T. G. Dekker, and W. Liebenberg, "Structure of a 1:1 complex between the anthelmintic drug mebendazole and propionic acid," J. Chem. Crystallogr., vol. 28, no. 1, pp. 11-15, 1998.

[62] F. T. Martins, P. P. Neves, J. Ellena, G. E. Camí, E. V. Brusau, and G. E. Narda, "Intermolecular contacts influencing the conformational and geometric features of the pharmaceutically preferred mebendazole polymorph C," J. Pharm. Sci., vol. 98, no. 7, pp. 2336-2344, 2009. 
[63] F. F. Ferreira, S. G. Antonio, P. C. P. Rosa, and C. de Oliveira Paiva-Santos, "Crystal structure determination of mebendazole form a using high-resolution synchrotron x-ray powder diffraction data," $J$. Pharm. Sci., vol. 99, no. 4, pp. 1734-1744, 2010.

[64] R. Aguayo-Ortiz, O. Méndez-Lucio, A. Romo-Mancillas, R. Castillo, L. Yépez-Mulia, J. L. Medina-Franco, and A. Hernández-Campos, "Molecular basis for benzimidazole resistance from a novel $\beta$-tubulin binding site model," Journal of Molecular Graphics and Modelling, vol. 45, pp. 26-37, 2013.

[65] Z. Tan, L. Chen, and S. Zhang, "Comprehensive modeling and discovery of mebendazole as a novel TRAF2and NCK-interacting kinase inhibitor," Scientific Reports, vol. 6, no. 1, p. 33534, 2016.

[66] J. Ariey-Bonnet, K. Carrasco, M. Le Grand, L. Hoffer, S. Betzi, M. Feracci, P. Tsvetkov, F. Devred, Y. Collette, X. Morelli, P. Ballester, and E. Pasquier, "In silico molecular target prediction unveils mebendazole as a potent MAPK14 inhibitor," Molecular Oncology, vol. 14, no. 12, pp. 3083-3099, 2020.

[67] A. A. Al-Karmalawy and M. Khattab, "Molecular modelling of mebendazole polymorphs as a potential colchicine binding site inhibitor," New J. Chem., vol. 44, pp. 13990-13996, 2020.

[68] F. Aberger, E. Hutterer, C. Sternberg, P. J. Del Burgo, and T. N. Hartmann, "Acute myeloid leukemia - strategies and challenges for targeting oncogenic hedgehog/gli signaling.," Cell communication and signaling : CCS, vol. 15, p. 8, Jan 2017.

[69] J. Wellbrock, E. Latuske, J. Köhler, K. Wagner, H. Stamm, E. Vettorazzi, G. Vohwinkel, M. Klokow, R. Uibeleisen, P. Ehm, K. Riecken, S. Loges, F. Thol, C. Schubert, M. Amling, M. Jücker, C. Bokemeyer, M. Heuser, J. Krauter, and W. Fiedler, "Expression of hedgehog pathway mediator gli represents a negative prognostic marker in human acute myeloid leukemia and its inhibition exerts antileukemic effects.," Clinical cancer research : an official journal of the American Association for Cancer Research, vol. 21, pp. 2388-98, May 2015.

[70] W. J. Hehre, R. Ditchfield, and J. A. Pople, "Self-consistent molecular orbital methods. XII. further extensions of gaussian-type basis sets for use in molecular orbital studies of organic molecules," The Journal of Chemical Physics, vol. 56, no. 5, pp. 2257-2261, 1972.

[71] C. Møller and M. S. Plesset, "Note on an approximation treatment for many-electron systems," Phys. Rev., vol. 46, pp. 618-622, 1934.

[72] R. A. Kendall, T. H. Dunning, and R. J. Harrison, "Electron affinities of the first-row atoms revisited. systematic basis sets and wave functions," J. Chem. Phys., vol. 96, no. 9, pp. 6796-6806, 1992.

[73] M. Feyereisen, G. Fitzgerald, and A. Komornicki, "Use of approximate integrals in ab initio theory. an application in MP2 energy calculations," Chem. Phys. Lett., vol. 208, no. 5, pp. 359-363, 1993.

[74] O. Vahtras, J. Almlöf, and M. Feyereisen, "Integral approximations for LCAO-SCF calculations," Chem. Phys. Lett., vol. 213, no. 5, pp. 514-518, 1993.

[75] S. Ten-no and S. Iwata, "Three-center expansion of electron repulsion integrals with linear combination of atomic electron distributions," Chem Phys Lett, vol. 240, no. 5, pp. 578-584, 1995.

[76] F. Weigend, "A fully direct RI-HF algorithm: Implementation, optimised auxiliary basis sets, demonstration of accuracy and efficiency," Phys. Chem. Chem. Phys., vol. 4, pp. 4285-4291, 2002.

[77] F. Weigend, A. Köhn, and C. Hättig, "Efficient use of the correlation consistent basis sets in resolution of the identity MP2 calculations," J. Chem. Phys., vol. 116, no. 8, pp. 3175-3183, 2002.

[78] R. M. Parrish, L. A. Burns, D. G. A. Smith, A. C. Simmonett, A. E. DePrince, E. G. Hohenstein, U. Bozkaya, A. Y. Sokolov, R. Di Remigio, R. M. Richard, J. F. Gonthier, A. M. James, H. R. McAlexander, A. Kumar, M. Saitow, X. Wang, B. P. Pritchard, P. Verma, H. F. Schaefer, K. Patkowski, R. A. King, E. F. Valeev, F. A. Evangelista, J. M. Turney, T. D. Crawford, and C. D. Sherrill, "Psi4 1.1: An open-source electronic structure program emphasizing automation, advanced libraries, and interoperability," J. Chem. Theory Comput., vol. 13, no. 7, pp. 3185-3197, 2017.

[79] H. M. Berman, J. Westbrook, Z. Feng, G. Gilliland, T. N. Bhat, H. Weissig, I. N. Shindyalov, and P. E. Bourne, "The Protein Data Bank," Nucleic Acids Res., vol. 28, no. 1, pp. 235-242, 2000. 
[80] S. K. Burley, H. M. Berman, C. Bhikadiya, C. Bi, L. Chen, L. Di Costanzo, C. Christie, K. Dalenberg, J. M. Duarte, S. Dutta, Z. Feng, S. Ghosh, D. S. Goodsell, R. K. Green, V. Guranović, D. Guzenko, B. P. Hudson, T. Kalro, Y. Liang, R. Lowe, H. Namkoong, E. Peisach, I. Periskova, A. Prlić, C. Randle, A. Rose, P. Rose, R. Sala, M. Sekharan, C. Shao, L. Tan, Y.-P. Tao, Y. Valasatava, M. Voigt, J. Westbrook, J. Woo, H. Yang, J. Young, M. Zhuravleva, and C. Zardecki, "RCSB protein data bank: biological macromolecular structures enabling research and education in fundamental biology, biomedicine, biotechnology and energy," Nucleic Acids Res., vol. 47, no. D1, pp. D464-D474, 2019.

[81] N. O’Boyle, M. Banck, C. James, C. Morley, T. Vandermeersch, and G. Hutchison, "Open babel: An open chemical toolbox," Journal of Cheminformatics, vol. 3, no. 1, p. 33, 2011.

[82] "The open babel package, version 2.3.2." http://openbabel.org, accessed Aug 2020.

[83] W. L. DeLano and Schrödinger, LLC, "The PyMOL molecular graphics system, version 2.5." https://pymol.org and https://github.com/schrodinger/pymol-open-source, accessed Aug 2020.

[84] J. M. Word, S. C. Lovell, T. H. LaBean, H. C. Taylor, M. E. Zalis, B. K. Presley, J. S. Richardson, and D. C. Richardson, "Visualizing and quantifying molecular goodness-of-fit: small-probe contact dots with explicit hydrogen atoms," Journal of Molecular Biology, vol. 285, no. 4, pp. 1711-1733, 1999.

[85] J. Word, S. C. Lovell, J. S. Richardson, and D. C. Richardson, "Asparagine and glutamine: using hydrogen atom contacts in the choice of side-chain amide orientation," Journal of Molecular Biology, vol. 285, no. 4, pp. 1735-1747, 1999.

[86] I. W. Davis, A. Leaver-Fay, V. B. Chen, J. N. Block, G. J. Kapral, X. Wang, L. W. Murray, I. Arendall, W. Bryan, J. Snoeyink, J. S. Richardson, and D. C. Richardson, "MolProbity: all-atom contacts and structure validation for proteins and nucleic acids," Nucleic Acids Research, vol. 35, no. suppl_2, pp. W375W383, 2007.

[87] V. B. Chen, W. B. Arendall, III, J. J. Headd, D. A. Keedy, R. M. Immormino, G. J. Kapral, L. W. Murray, J. S. Richardson, and D. C. Richardson, "MolProbity: all-atom structure validation for macromolecular crystallography," Acta Crystallographica Section D, vol. 66, no. 1, pp. 12-21, 2010.

[88] M. J. Vainio, J. S. Puranen, and M. S. Johnson, "ShaEP: Molecular overlay based on shape and electrostatic potential," Journal of Chemical Information and Modeling, vol. 49, no. 2, pp. 492-502, 2009.

[89] C. I. Bayly, P. Cieplak, W. Cornell, and P. A. Kollman, "A well-behaved electrostatic potential based method using charge restraints for deriving atomic charges: the RESP model," The Journal of Physical Chemistry, vol. 97, no. 40, pp. 10269-10280, 1993.

[90] W. D. Cornell, P. Cieplak, C. I. Bayly, and P. A. Kollmann, "Application of RESP charges to calculate conformational energies, hydrogen bond energies, and free energies of solvation," Journal of the American Chemical Society, vol. 115, no. 21, pp. 9620-9631, 1993.

[91] A. Alenaizan, L. A. Burns, and C. D. Sherrill, "Python implementation of the restrained electrostatic potential charge model," International Journal of Quantum Chemistry, vol. 0, no. 0, p. e26035, 2019.

[92] J. A. Maier, C. Martinez, K. Kasavajhala, L. Wickstrom, K. E. Hauser, and C. Simmerling, "ff14SB: Improving the accuracy of protein side chain and backbone parameters from ff99SB," Journal of Chemical Theory and Computation, vol. 11, no. 8, pp. 3696-3713, 2015.

[93] L.-P. Wang, K. A. McKiernan, J. Gomes, K. A. Beauchamp, T. Head-Gordon, J. E. Rice, W. C. Swope, T. J. Martínez, and V. S. Pande, "Building a more predictive protein force field: A systematic and reproducible route to AMBER-FB15," The Journal of Physical Chemistry B, vol. 121, no. 16, pp. 4023-4039, 2017.

[94] "Gaff2." http://ambermd.org, 2019.

[95] J. D. Schmit, N. L. Kariyawasam, V. Needham, and P. E. Smith, "SLTCAP: A simple method for calculating the number of ions needed for MD simulation," Journal of Chemical Theory and Computation, vol. 14, no. 4, pp. 1823-1827, 2018.

[96] D. Case, I. Ben-Shalom, S. Brozell, D. Cerutti, T. Cheatham, III, V. Cruzeiro, T. Darden, R. Duke, D. Ghoreishi, G. Giambasu, T. Giese, M. Gilson, H. Gohlke, A. Goetz, D. Greene, R. Harris, N. Homeyer, Y. Huang, S. Izadi, A. Kovalenko, R. Krasny, T. Kurtzman, T. Lee, S. LeGrand, P. Li, C. Lin, J. Liu, T. Luchko, R. Luo, V. Man, D. Mermelstein, K. Merz, Y. Miao, G. Monard, C. Nguyen, H. Nguyen, A. Onufriev, F. Pan, R. Qi, D. Roe, A. Roitberg, C. Sagui, S. Schott-Verdugo, J. Shen, C. Simmerling, 
J. Smith, J. Swails, R. Walker, J. Wang, H. Wei, L. Wilson, R. Wolf, X. Wu, L. Xiao, Y. Xiong, D. York, P. K. D. Case, R. Betz, W. Botello-Smith, D. Cerutti, T. Cheatham and III, T. Darden, R. Duke, T. Giese, H. Gohlke, A. Goetz, N. Homeyer, S. Izadi, P. Janowski, J. Kaus, A. Kovalenko, T. Lee, S. LeGrand, P. Li, C. Lin, T. Luchko, R. Luo, B. Madej, D. Mermelstein, K. Merz, G. Monard, H. Nguyen, H. Nguyen, I. Omelyan, A. Onufriev, D. Roe, A. Roitberg, C. Sagui, C. Simmerling, J. Swails, R. Walker, J. Wang, R. Wolf, X. Wu, L. Xiao, D. York, and P. Kollman, "AMBER19." http://ambermd.org, 2019. University of California, San Francisco.

[97] R. W. Pastor, B. R. Brooks, and A. Szabo, "An analysis of the accuracy of langevin and molecular dynamics algorithms," Molecular Physics, vol. 65, no. 6, pp. 1409-1419, 1988.

[98] R. Anandakrishnan, A. Drozdetski, R. C. Walker, and A. V. Onufriev, "Speed of conformational change: comparing explicit and implicit solvent molecular dynamics simulations," Biophysical journal, vol. 108, no. 25762327, pp. 1153-1164, 2015.

[99] U. Essmann, L. Perera, M. L. Berkowitz, T. Darden, H. Lee, and L. G. Pedersen, "A smooth particle mesh ewald method," Journal Of Chemical Physics, vol. 103, no. 19, pp. 8577-8593, 1995.

[100] J.-P. Ryckaert, G. Ciccotti, and H. J. Berendsen, "Numerical integration of the cartesian equations of motion of a system with constraints: molecular dynamics of n-alkanes," Journal of Computational Physics, vol. 23, no. 3, pp. 327-341, 1977.

[101] R. Salomon-Ferrer, A. W. Götz, D. Poole, S. Le Grand, and R. C. Walker, "Routine microsecond molecular dynamics simulations with AMBER on GPUs. 2. explicit solvent particle mesh ewald," Journal of Chemical Theory and Computation, vol. 9, no. 9, pp. 3878-3888, 2013.

[102] S. Le Grand, A. W. Götz, and R. C. Walker, "SPFP: Speed without compromise-a mixed precision model for GPU accelerated molecular dynamics simulations," Computer Physics Communications, vol. 184, no. 2, pp. 374-380, 2013.

[103] D. R. Roe and T. E. Cheatham, "PTRAJ and CPPTRAJ: Software for processing and analysis of molecular dynamics trajectory data," Journal of Chemical Theory and Computation, vol. 9, no. 7, pp. 3084-3095, 2013.

[104] W. Kabsch and C. Sander, "Dictionary of protein secondary structure: Pattern recognition of hydrogenbonded and geometrical features," Biopolymers, vol. 22, no. 12, pp. 2577-2637, 1983.

[105] J. Shao, S. W. Tanner, N. Thompson, and T. E. Cheatham, "Clustering molecular dynamics trajectories: 1. characterizing the performance of different clustering algorithms," Journal of Chemical Theory and Computation, vol. 3, no. 6, pp. 2312-2334, 2007.

[106] B. R. Miller, T. D. McGee, J. M. Swails, N. Homeyer, H. Gohlke, and A. E. Roitberg, "MMPBSA.py: An efficient program for end-state free energy calculations," Journal of Chemical Theory and Computation, vol. 8, no. 9, pp. 3314-3321, 2012.

[107] A. Onufriev, D. Bashford, and D. A. Case, "Exploring protein native states and large-scale conformational changes with a modified generalized born model," Proteins: Structure, Function, and Bioinformatics, vol. 55, no. 2, pp. 383-394, 2004.

[108] B. W. Dymock, X. Barril, P. A. Brough, J. E. Cansfield, A. Massey, E. McDonald, R. E. Hubbard, A. Surgenor, S. D. Roughley, P. Webb, P. Workman, L. Wright, and M. J. Drysdale, "Novel, potent small-molecule inhibitors of the molecular chaperone Hsp90 discovered through structure-based design," Journal of Medicinal Chemistry, vol. 48, no. 13, pp. 4212-4215, 2005.

[109] C. M. McBride, B. Levine, Y. Xia, C. Bellamacina, T. Machajewski, Z. Gao, P. Renhowe, W. AntoniosMcCrea, P. Barsanti, K. Brinner, A. Costales, B. Doughan, X. Lin, A. Louie, M. McKenna, K. Mendenhall, D. Poon, A. Rico, M. Wang, T. E. Williams, T. Abrams, S. Fong, T. Hendrickson, D. Lei, J. Lin, D. Menezes, N. Pryer, P. Taverna, Y. Xu, Y. Zhou, and C. M. Shafer, "Design, structure-activity relationship, and in vivo characterization of the development candidate NVP-HSP990," Journal of Medicinal Chemistry, vol. 57, no. 21, pp. 9124-9129, 2014.

[110] M. M. U. Ali, S. M. Roe, C. K. Vaughan, P. Meyer, B. Panaretou, P. W. Piper, C. Prodromou, and L. H. Pearl, "Crystal structure of an Hsp90-nucleotide-p23/Sba1 closed chaperone complex," Nature, vol. 440, no. 7087, pp. 1013-1017, 2006. 
[111] A. K. Shiau, S. F. Harris, D. R. Southworth, and D. A. Agard, "Structural analysis of E. coli hsp90 reveals dramatic nucleotide-dependent conformational rearrangements," Cell, vol. 127, no. 2, pp. 329-340, 2006.

[112] C. Prodromou, "Mechanisms of Hsp90 regulation," Biochemical Journal, vol. 473, no. 16, pp. 2439-2452, 2016. 


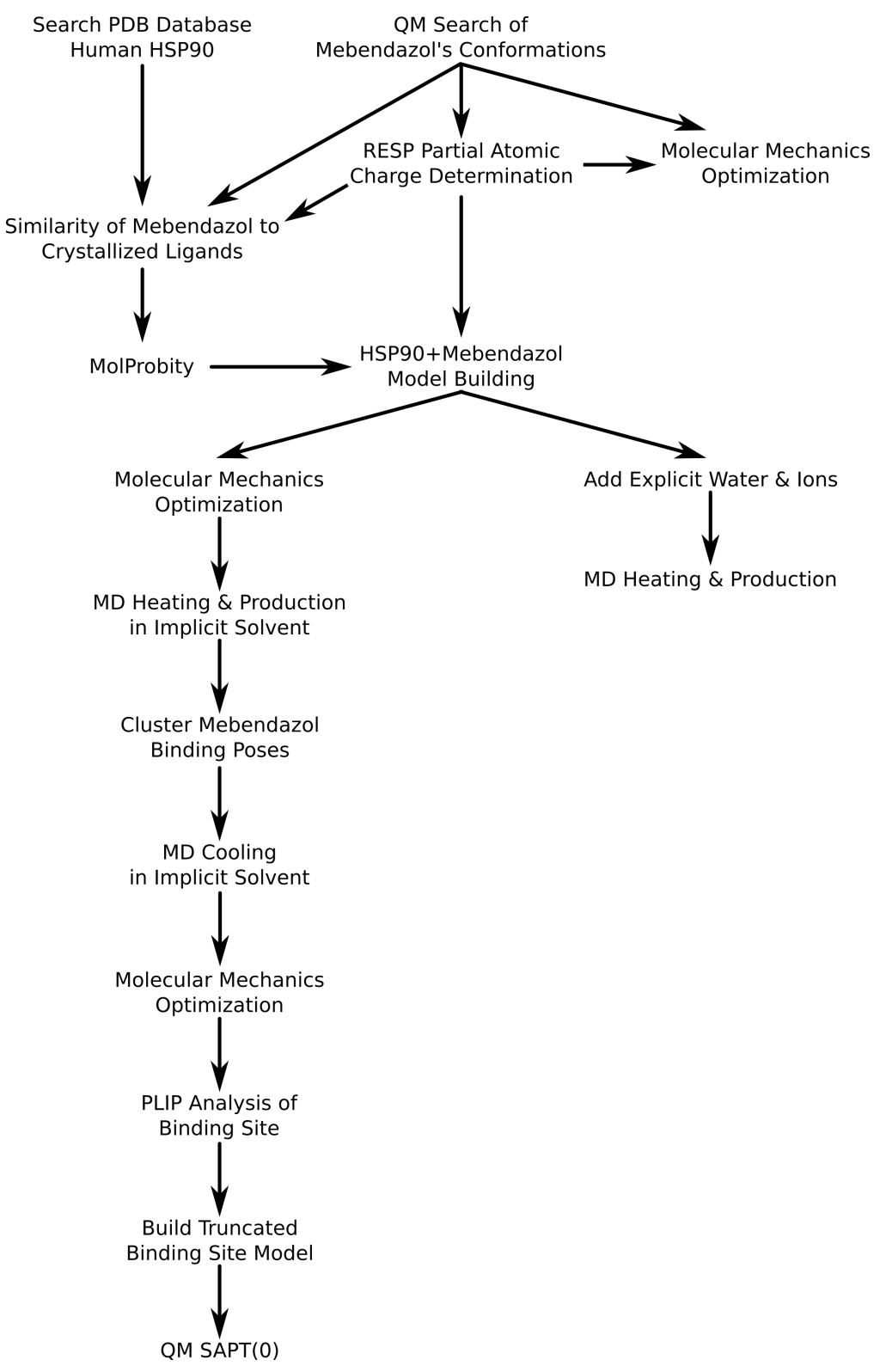

Figure S1: A schematic of the workflow used in this study.

\section{Supplementary Information}


Table S1. The PDB ID code [80] for the crystal structure of Hsp90 human proteins that are bound with ligands.

\begin{tabular}{|c|c|c|c|c|c|c|c|c|c|}
\hline $1 B Y Q$ & 1ELW & $1 \mathrm{OSF}$ & 1UY6 & 1UY7 & 1UY8 & 1UY9 & $1 \mathrm{UYC}$ & 1UYD & $1 \mathrm{UYE}$ \\
\hline $1 \mathrm{UYF}$ & $1 \mathrm{UYG}$ & $1 \mathrm{UYH}$ & 1UYI & 1UYK & $1 \mathrm{UYM}$ & 1YC3 & 1YET & 2BSM & $2 \mathrm{BT} 0$ \\
\hline $2 \mathrm{BYH}$ & 2BYI & $2 \mathrm{BZ} 5$ & $2 \mathrm{CCS}$ & $2 \mathrm{CCT}$ & $2 \mathrm{CCU}$ & $2 \mathrm{FWY}$ & $2 \mathrm{FWZ}$ & $2 \mathrm{H} 55$ & 2.JJC \\
\hline $2 \mathrm{QF} 6$ & $2 \mathrm{QFO}$ & 2QG0 & 2QG2 & 2UWD & 2VCI & 2VCJ & 2WI1 & 2WI2 & $2 \mathrm{WI} 3$ \\
\hline 2WI4 & $2 \mathrm{WI} 5$ & 2WI6 & 2WI7 & $2 \mathrm{XAB}$ & 2XDK & $2 \mathrm{XDL}$ & 2XDS & $2 \mathrm{XDU}$ & $2 \mathrm{XDX}$ \\
\hline 2XHR & $2 \mathrm{XHT}$ & 2XHX & 2XJG & 2XJJ & 2XJX & XK2 & 2YE2 & 2YE3 & 2YE4 \\
\hline 2YE5 & 2YE6 & 2YE7 & 2YE8 & 2YE9 & 2YEA & $2 \mathrm{YEB}$ & 2YEC & 2YED & $2 \mathrm{YEE}$ \\
\hline $2 \mathrm{YEF}$ & $2 \mathrm{YEG}$ & $2 \mathrm{YEH}$ & $2 \mathrm{YEI}$ & 2YEJ & 2YI0 & 2YI5 & 2 YI6 & 2YI7 & 2 YJW \\
\hline 2YJX & 2YK2 & 2YK9 & $2 \mathrm{YKB}$ & $2 \mathrm{YKC}$ & $2 \mathrm{YKE}$ & $2 \mathrm{YKI}$ & $2 \mathrm{YKJ}$ & $3 \mathrm{~B} 24$ & $3 \mathrm{~B} 25$ \\
\hline $3 \mathrm{~B} 26$ & 3B27 & $3 \mathrm{~B} 28$ & 3BM9 & $3 \mathrm{BMY}$ & 3D0B & $3 \mathrm{EKO}$ & $3 \mathrm{EKR}$ & $3 \mathrm{FT} 5$ & $3 \mathrm{FT} 8$ \\
\hline 3HEK & $3 \mathrm{HHU}$ & $3 \mathrm{HYY}$ & $3 \mathrm{HYZ}$ & $3 \mathrm{HZ1}$ & $3 \mathrm{HZ} 5$ & 3INW & 3INX & $3 \mathrm{~K} 97$ & $3 \mathrm{~K} 98$ \\
\hline 3К99 & $3 \mathrm{MNR}$ & $3 \mathrm{NMQ}$ & $3 \mathrm{O} 0 \mathrm{I}$ & $3 \mathrm{O}$ & $3 \mathrm{O} 5 \mathrm{R}$ & 3OW6 & $3 \mathrm{OWB}$ & 3OWD & 3QTF \\
\hline 3R91 & 3R92 & 3RKZ & 3RLP & 3RLQ & 3RLR & $3 \mathrm{~T} 0 \mathrm{Z}$ & $3 \mathrm{~T} 10$ & $3 \mathrm{~T} 1 \mathrm{~K}$ & $3 \mathrm{~T} 2 \mathrm{~S}$ \\
\hline $3 \mathrm{TUH}$ & $3 \mathrm{VHA}$ & $3 \mathrm{VHC}$ & $3 \mathrm{VHD}$ & $3 \mathrm{WHA}$ & 3WQ9 & $4 \mathrm{AWO}$ & 4AWP & $4 \mathrm{AWQ}$ & $4 \mathrm{~B} 7 \mathrm{P}$ \\
\hline $4 \mathrm{BQG}$ & 4BQJ & $4 \mathrm{CWF}$ & $4 \mathrm{CWN}$ & $4 \mathrm{CWO}$ & 4CWP & $4 \mathrm{CWQ}$ & $4 \mathrm{CWR}$ & 4CWS & $4 \mathrm{CWT}$ \\
\hline $4 \mathrm{DRH}$ & 4DRI & 4DRJ & $4 \mathrm{DRK}$ & 4DRM & $4 \mathrm{DRN}$ & $4 \mathrm{DRP}$ & $4 \mathrm{EEH}$ & $4 \mathrm{EFT}$ & $4 \mathrm{EFU}$ \\
\hline $4 \mathrm{EGH}$ & 4EGK & $4 \mathrm{FCP}$ & $4 \mathrm{FCQ}$ & $4 \mathrm{FCR}$ & $4 \mathrm{HY} 6$ & 4JFI & $\mathrm{FJ}$ & 4JFK & 4JFL \\
\hline 4JFM & 4JQL & $4 \mathrm{~L} 8 \mathrm{Z}$ & 4L90 & 4L91 & 4L93 & 4L94 & $4 \mathrm{LAX}$ & $4 \mathrm{LAY}$ & 4LWE \\
\hline $4 \mathrm{LWF}$ & $4 \mathrm{LWG}$ & $4 \mathrm{LWH}$ & 4LWI & $4 \mathrm{NH} 7$ & $4 \mathrm{NH} 8$ & 4NH9 & $4 \mathrm{O} 04$ & $4 \mathrm{O} 05$ & $4 \mathrm{O} 07$ \\
\hline $4 \mathrm{O} 09$ & $400 \mathrm{~B}$ & $4 \mathrm{O} 33$ & $4 \mathrm{R} 3 \mathrm{M}$ & 4TW6 & 4TW7 & 4TX0 & 4U93 & $4 \mathrm{~W} 7 \mathrm{~T}$ & $4 \mathrm{~W} 9 \mathrm{O}$ \\
\hline 4W9P & $4 \mathrm{~W} 9 \mathrm{Q}$ & $4 \mathrm{Z} 1 \mathrm{~F}$ & $4 \mathrm{Z} 1 \mathrm{G}$ & $4 \mathrm{Z} 1 \mathrm{H}$ & 4Z1I & $5 \mathrm{BXJ}$ & $5 \mathrm{CF} 0$ & 5 DIT & $5 \mathrm{DIU}$ \\
\hline $5 \mathrm{DIV}$ & $5 \mathrm{~F} 5 \mathrm{R}$ & $5 \mathrm{FNC}$ & $5 \mathrm{FND}$ & $5 \mathrm{FNF}$ & $5 \mathrm{GGZ}$ & $5 \mathrm{HPH}$ & $5 \mathrm{~J} 20$ & $5 \mathrm{~J} 27$ & $5 \mathrm{~J} 2 \mathrm{X}$ \\
\hline $5 \mathrm{~J} 64$ & $5 \mathrm{~J} 6 \mathrm{~L}$ & $5 \mathrm{~J} 6 \mathrm{M}$ & $5 \mathrm{~J} 6 \mathrm{~N}$ & $5 \mathrm{~J} 82$ & $5 \mathrm{~J} 86$ & $5 \mathrm{~J} 8 \mathrm{M}$ & 5J9X & $5 \mathrm{LNY}$ & $5 \mathrm{LNZ}$ \\
\hline $5 \mathrm{LO} 0$ & $5 \mathrm{LO} 1$ & $5 \mathrm{LO} 5$ & $5 \mathrm{LO} 6$ & $5 \mathrm{~L}($ & 5LR1 & 5LR7 & $5 \mathrm{LRL}$ & $5 \mathrm{LRZ}$ & 5LS1 \\
\hline $5 \mathrm{M} 4 \mathrm{E}$ & $5 \mathrm{M} 4 \mathrm{H}$ & $5 \mathrm{M} 4 \mathrm{~K}$ & $5 \mathrm{M} 4 \mathrm{M}$ & $5 \mathrm{M} 4 \mathrm{~N}$ & $5 \mathrm{M} 4 \mathrm{P}$ & $5 \mathrm{NYH}$ & $5 \mathrm{NYI}$ & $5 \mathrm{OBK}$ & $5 \mathrm{OCI}$ \\
\hline 5OD7 & $5 \mathrm{ODX}$ & $5 \mathrm{~T} 21$ & $5 \mathrm{UC} 4$ & $5 \mathrm{UC}$ & $5 \mathrm{UCI}$ & $5 \mathrm{UCJ}$ & $5 \mathrm{VYY}$ & $5 \mathrm{XQD}$ & $5 \mathrm{XQE}$ \\
\hline 5XR5 & $5 \mathrm{XR} 9$ & $5 \mathrm{XRB}$ & 5XRD & 5XRE & $5 \mathrm{Y} 3 \mathrm{~N}$ & $5 \mathrm{Y} 3 \mathrm{O}$ & 5ZR3 & 6B99 & $6 \mathrm{~B} 9 \mathrm{~A}$ \\
\hline $6 \mathrm{CEO}$ & $6 \mathrm{CYG}$ & $6 \mathrm{CYH}$ & 6FCJ & 6GP8 & $6 \mathrm{GPH}$ & $6 \mathrm{GPO}$ & 6GPP & $6 \mathrm{GPR}$ & $6 \mathrm{GPT}$ \\
\hline 6GQ6 & 6GQR & 6GQS & $6 \mathrm{GQU}$ & 6GR1 & 6GR3 & 6GR5 & & & \\
\hline
\end{tabular}


Table S2. The ID code for the ligands found in the crystal structures listed in Table S1

\begin{tabular}{|c|c|c|c|c|c|c|c|c|c|}
\hline $\mathrm{ADP}$ & LGA & XQI & YKC & P54 & H05 & RL1 & 3JP & $70 \mathrm{~L}$ & $9 \mathrm{QY}$ \\
\hline TRS & A56 & VXX & YKE & $1 \mathrm{PE}$ & $6 \mathrm{LV}$ & RL3 & H71 & $70 \mathrm{M}$ & $8 \mathrm{CF}$ \\
\hline KOS & A13 & $2 \mathrm{FY}$ & YKI & FK5 & T62 & X29 & $94 \mathrm{M}$ & $70 \mathrm{O}$ & $8 \mathrm{CO}$ \\
\hline MPD & A51 & $2 \mathrm{~A} 7$ & YKJ & MEX & TV2 & S36 & $4 \mathrm{KP}$ & $72 \mathrm{~K}$ & $8 \mathrm{CR}$ \\
\hline PU3 & A94 & $2 \mathrm{AE}$ & B2J & BSM & W2D & S46 & ANP & $72 \mathrm{Y}$ & $8 \mathrm{CU}$ \\
\hline PU4 & A91 & $2 \mathrm{GA}$ & B2K & MEY & HAJ & FK5 & NPO & 73J & $8 \mathrm{DU}$ \\
\hline PU5 & $2 \mathrm{GG}$ & 2D3 & B2L & $05 \mathrm{~S}$ & G3R & I63 & FJS & $73 S$ & $9 \mathrm{ZC}$ \\
\hline PU6 & 2GJ & 2D4 & $\mathrm{B} 2 \mathrm{~T}$ & $06 \mathrm{H}$ & IK9 & FJ2 & 5B8 & $73 \mathrm{Y}$ & JX1 \\
\hline PU7 & $2 \mathrm{EQ}$ & 2A9 & $\mathrm{B} 2 \mathrm{X}$ & 06J & RAP & FJ3 & $5 \mathrm{BG}$ & $73 Z$ & $8 \mathrm{MF}$ \\
\hline PU8 & $\mathrm{ZZ2}$ & $2 \mathrm{~K} 4$ & BXZ & $06 \mathrm{~T}$ & RAP & FJ4 & $5 \mathrm{BH}$ & 7F9 & $8 \mathrm{M} 9$ \\
\hline PU9 & ZZ3 & XQ0 & CXZ & $3 \mathrm{RP}$ & RAP & FJ5 & ANP & 7FX & 9J0 \\
\hline PU1 & ZZ3 & $\mathrm{ADE}$ & SNX & $3 R Q$ & I63 & FJ6 & IEE & 7F9 & NEC \\
\hline PU2 & ZZ4 & $2 \mathrm{EC}$ & PYU & $3 R R$ & $0 \mathrm{MC}$ & E0G & IQ5 & TF3 & PA7 \\
\hline PU0 & ZZ5 & ANP & PY9 & ATP & $0 \mathrm{MC}$ & $2 \mathrm{LC}$ & TQL & $7 \mathrm{FW}$ & D57 \\
\hline PUZ & ZZ6 & XQG & MO8 & $\mathrm{ACP}$ & $0 \mathrm{MD}$ & $2 \mathrm{LC}$ & $6 \mathrm{TN}$ & TF3 & $\mathrm{N} 5 \mathrm{O}$ \\
\hline PUX & $2 \mathrm{KL}$ & $2 \mathrm{KU}$ & MOJ & ANP & HH6 & 2Q8 & ANP & $7 \mathrm{FV}$ & N5A \\
\hline PU3 & VHD & XQI & BD0 & AGS & EFT & 2Q9 & $6 \mathrm{FJ}$ & TF3 & $\mathrm{D} 4 \mathrm{~W}$ \\
\hline $4 \mathrm{BC}$ & XDK & XQK & 819 & TUH & EFU & FGH & $6 \mathrm{FF}$ & $7 \mathrm{FE}$ & $\mathrm{APC}$ \\
\hline GDM & $2 \mathrm{DL}$ & XQK & $37 \mathrm{D}$ & MES & $0 O Y$ & $2 \mathrm{R} 6$ & $6 \mathrm{DL}$ & TF3 & A12 \\
\hline BSM & MT0 & ZZ3 & $42 \mathrm{C}$ & VHA & $\mathrm{RDC}$ & 2QA & $6 \mathrm{G} 7$ & 9EK & CMP \\
\hline CT5 & LGA & YI0 & $37 \mathrm{D}$ & VHC & $42 \mathrm{C}$ & $3 \mathrm{PG}$ & $6 \mathrm{GC}$ & $2 \mathrm{EQ}$ & $\mathrm{ADP}$ \\
\hline $2 \mathrm{D} 7$ & MT0 & YI5 & $42 \mathrm{C}$ & VHE & $2 \mathrm{~N} 6$ & TZN & $6 \mathrm{FJ}$ & $9 \mathrm{QN}$ & CMP \\
\hline $2 \mathrm{DD}$ & WOE & $6 \mathrm{QM}$ & Z64 & WHA & 0TM & JR9 & $6 \mathrm{FF}$ & $9 \mathrm{R} 8$ & A 12 \\
\hline AB4 & $\mathrm{C} 0 \mathrm{P}$ & BZ8 & JZB & YUK & FJ1 & $37 \mathrm{~L}$ & $6 \mathrm{GV}$ & HOT & $\mathrm{ADP}$ \\
\hline $4 \mathrm{BH}$ & $\mathrm{COY}$ & YJW & JZC & $99 \mathrm{~B}$ & $1 \mathrm{KT}$ & $37 \mathrm{~K}$ & $6 \mathrm{GW}$ & 9RZ & APC \\
\hline $2 \mathrm{E} 1$ & T5M & YJX & $4 \mathrm{CD}$ & $99 \mathrm{~A}$ & $1 \mathrm{KU}$ & 384 & $6 \mathrm{DL}$ & $74 \mathrm{E}$ & A 12 \\
\hline 2D9 & XJG & YJW & $1 \mathrm{RC}$ & 592 & JFK & 990 & $6 \mathrm{GC}$ & $83 \mathrm{~S}$ & CMP \\
\hline H64 & L81 & YJX & PFT & $9 \mathrm{UN}$ & $1 \mathrm{KY}$ & $3 \mathrm{JC}$ & $70 \mathrm{~K}$ & 871 & APC \\
\hline H71 & XJX & YK9 & SD1 & $50 \mathrm{Q}$ & $1 \mathrm{KZ}$ & $3 \mathrm{JQ}$ & $70 \mathrm{Z}$ & 874 & AN2 \\
\hline DZ8 & $\mathrm{ADP}$ & YKB & 7PP & XKL & VJ6 & $3 \mathrm{JR}$ & $70 \mathrm{~N}$ & KU3 & $\mathrm{ADP}$ \\
\hline
\end{tabular}




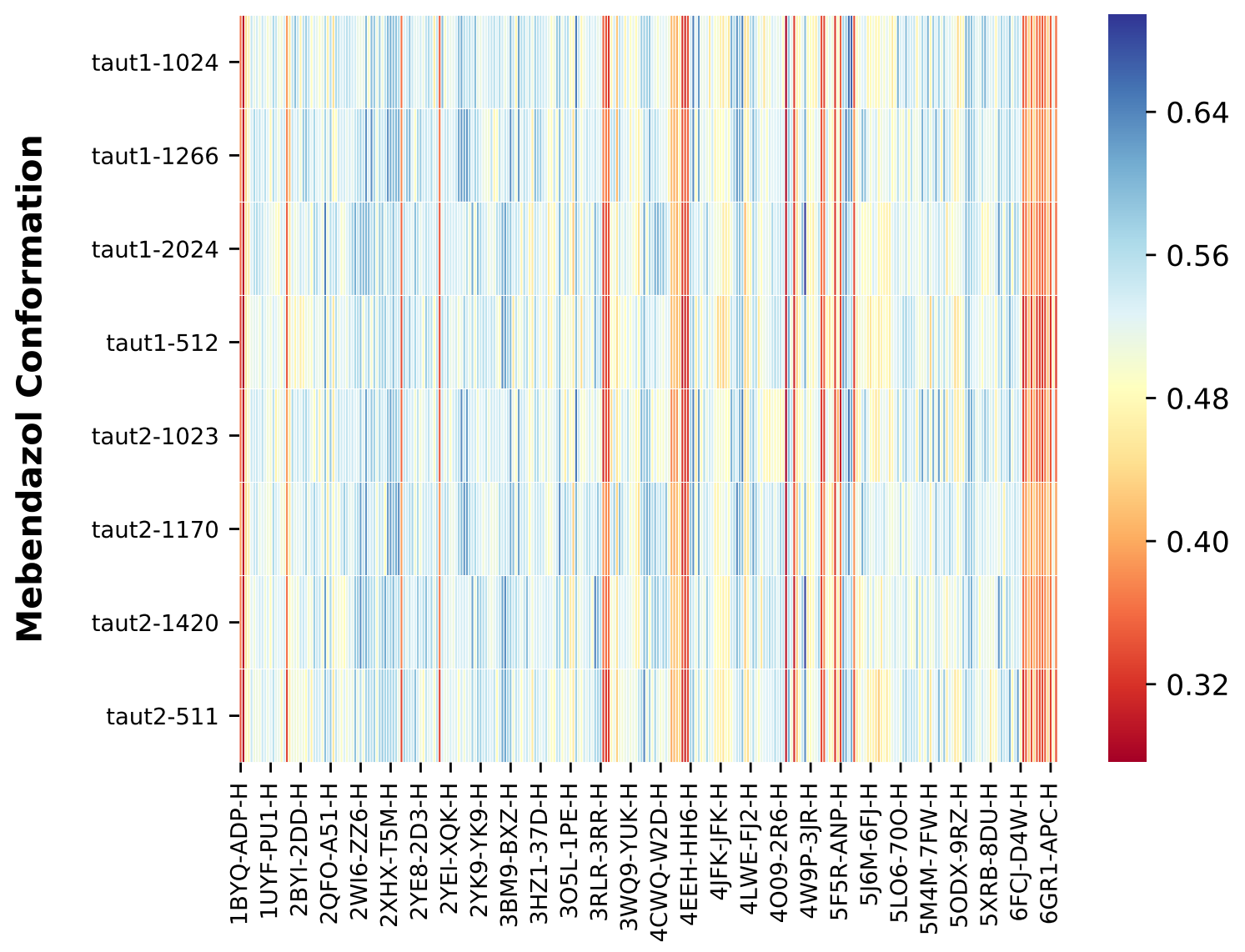

Crystal Ligand

Figure S2: Similarity indexes, computed using shape \& electrostatic criteria, between the eight lowest energy (MP2/AVTZ//MP2/AVTZ) mebendazole conformations and 300 ligands extracted from 287 crystals. 


\section{WI6-fb15 pose 0}
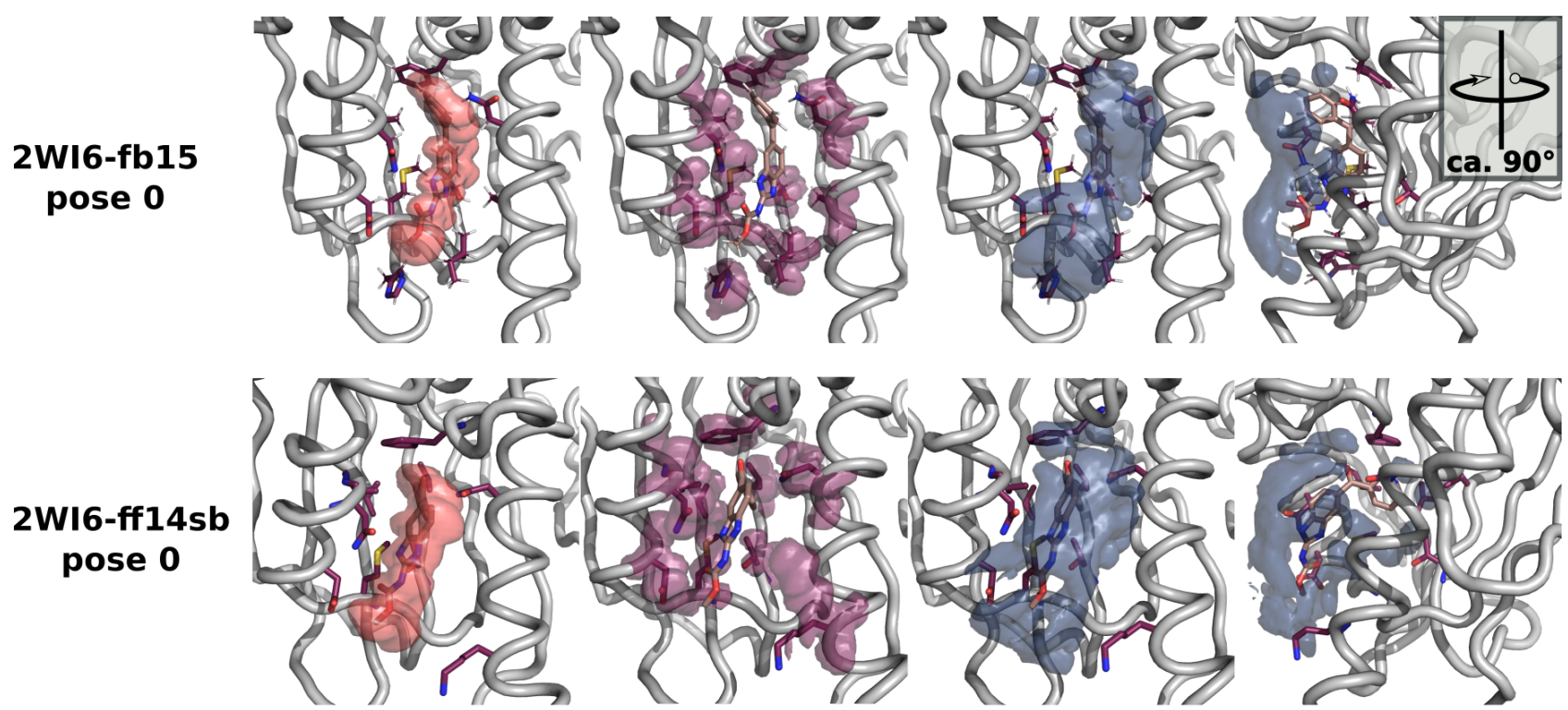

2WI6-ff14sb pose 1
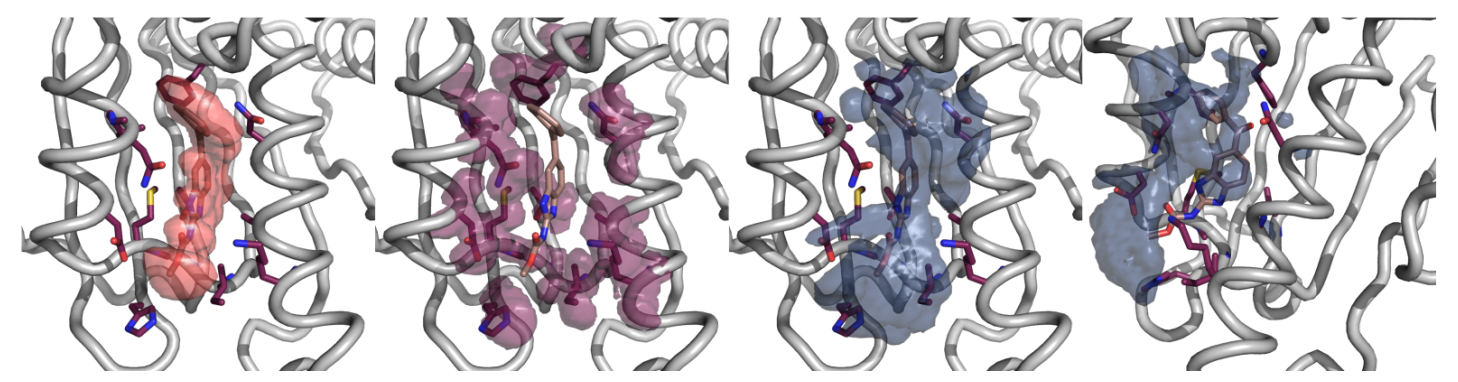

Figure S3: The spatial distribution of mebendazole (orange isosurface), binding pocket amino acids (purple) and two orientations of the close waters (blue) for the 2WI6 simulations, showing a normalized occupancy density (molecule $/ \AA^{3}$ ) of $80 \%$. 


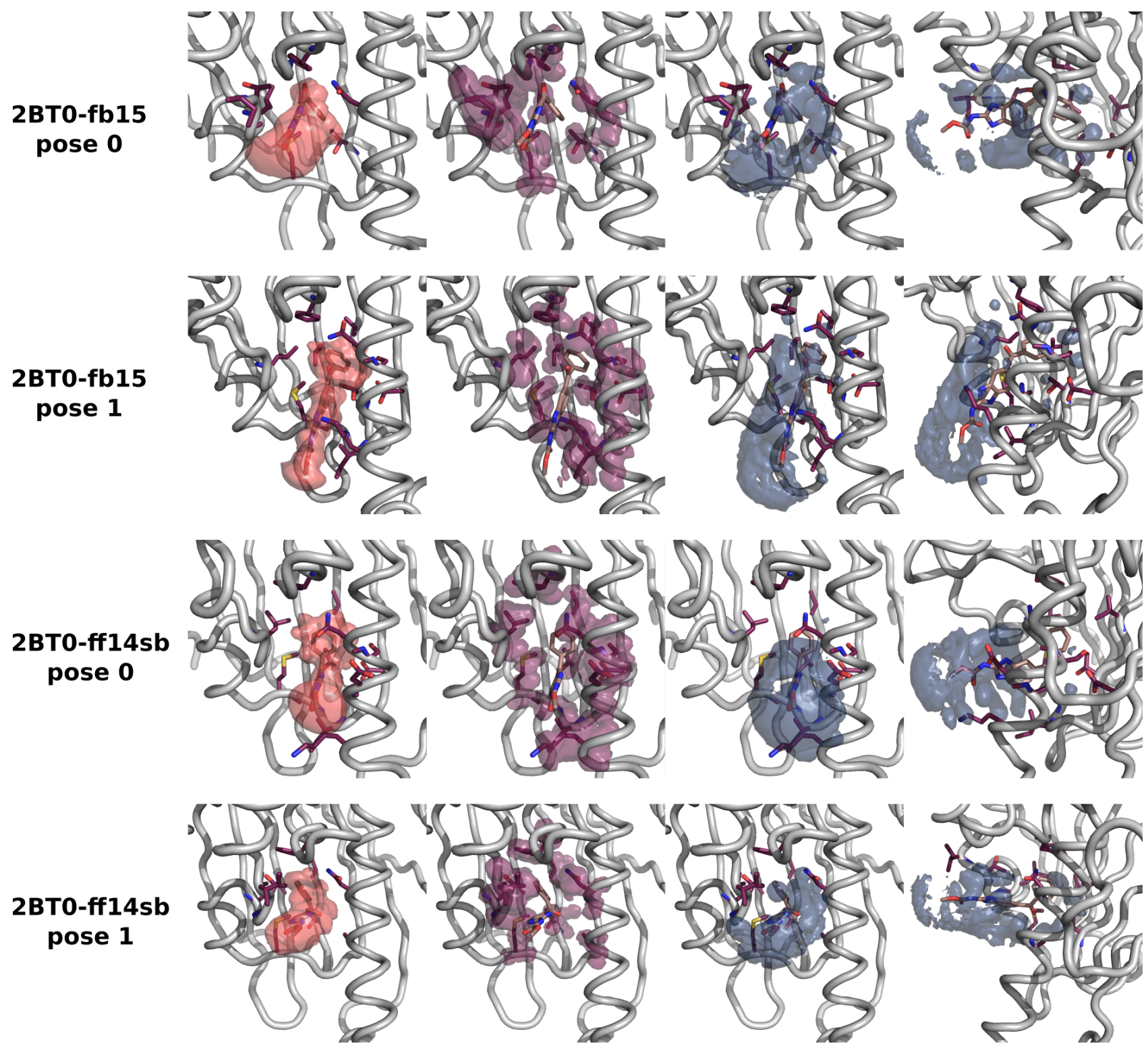

Figure S4: The spatial distribution for the 2BT0 simulations.

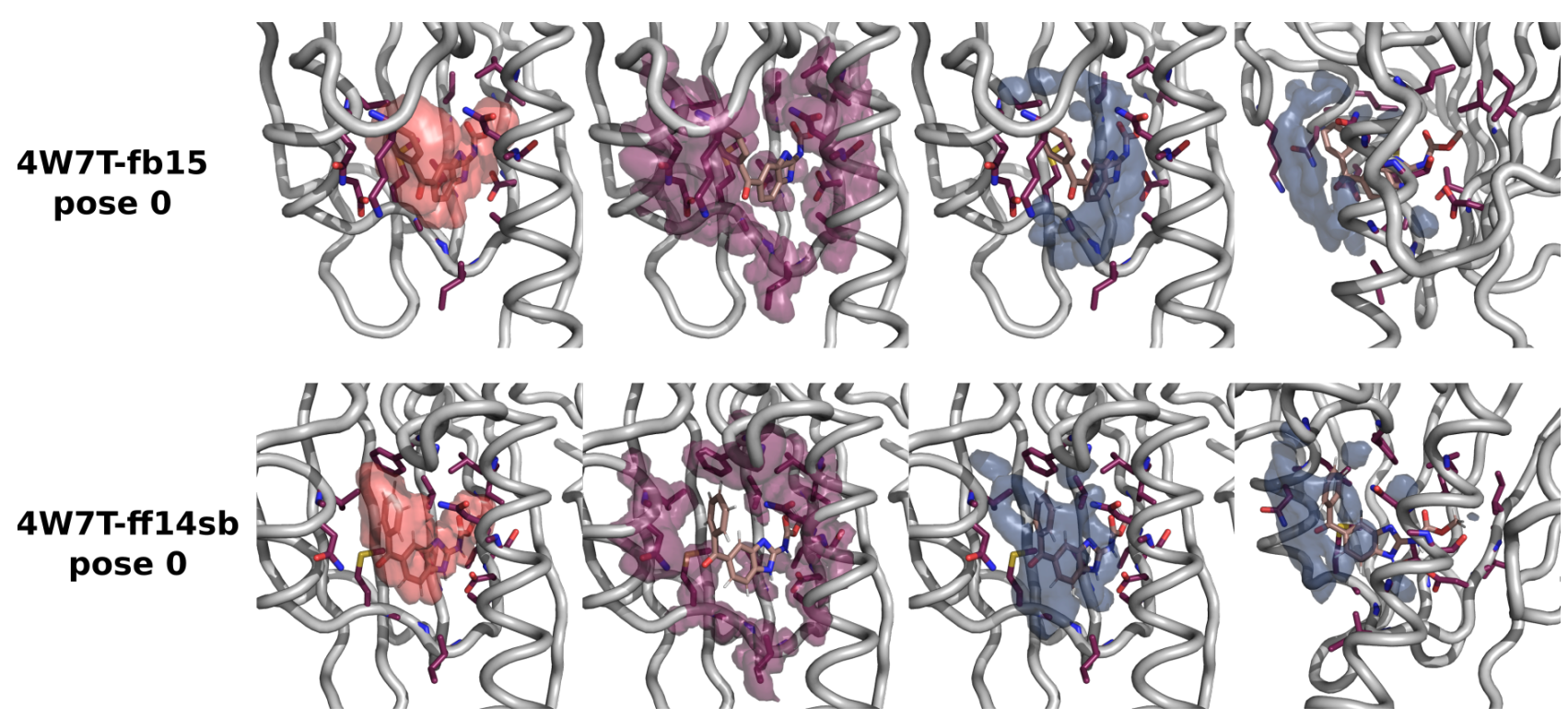

Figure S5: The spatial distribution for the $4 \mathrm{~W} 7 \mathrm{~T}$ simulations. 
16

\begin{tabular}{|c|c|c|c|c|c|c|}
\hline Amino & Acid & EVETFAFQAE & IAQLMSLIIN & TFYSNKEIFL & RELISNSSDA & LDKIRYESLT \\
\hline $2 \mathrm{WI} 6$, & $\mathrm{fb} 15$ & EEEEE $\quad \mathrm{HH}$ & НнНнНнННТТ & S S GTGHH & НHНHНHНHНH & НHНHнHнHТН \\
\hline 2 WI6, & $\mathrm{ff} 14 \mathrm{sb}$ & EEEEE & НHHHHHHHHH & S GGGHH & НHHHHHHHHH & НHНHНHНTTT \\
\hline 2Вт0, & $\mathrm{fb} 15$ & EEEEE & HНHHHHHHTS & S GGGHH & ННHНHнHнHН & НHНHНHНTТT \\
\hline 2ВT0, & $\mathrm{ff} 14 \mathrm{sb}$ & EEEE & НHHHHHHHHH & S GGGHH & НHHHHHHHHH & НHНHНHНHHT \\
\hline $4 \mathrm{~W} 7 \mathrm{~T}$, & $\mathrm{fb} 15$ & EEEE & НнНннНнНнТ & S GGGGG & ННнНнНнНHН & НнНHнНнНтТ \\
\hline $4 \mathrm{~W} 7 \mathrm{~T}$, & $\mathrm{ff} 14 \mathrm{sb}$ & EEEE & НHHHHHHHHH & S TTHHH & НHHHHHHHHH & НHНHHHHHTT \\
\hline & & 66 & & & & \\
\hline Amino & Acid & DPSKLDSGKE & LHINLIPNKQ & DRTLTIVDTG & IGMTKADLIN & NLGTIAKSGT \\
\hline 2 WI6, & $\mathrm{fb} 15$ & GGGGTT & EEEEEETT & TTEEEEEE $\mathrm{S}$ & нннннН & нТТТТТнннн \\
\hline 2 WI6, & $\mathrm{ff} 14 \mathrm{sb}$ & THнHнTSS & EEEEEETT & TTEEEEEE $\mathrm{S}$ & НнНнHН & нHTSSTHннн \\
\hline 2Вт0, & $\mathrm{fb} 15$ & GHнHTT & EEEEEETT T & TTEEEEEE $\mathrm{S}$ & НнНнНТ & GGG НHнHн \\
\hline 2вт0, & $\mathrm{ff} 14 \mathrm{sb}$ & тннннт & EEEEEETT T & TTEEEEEE $S$ & нннннт & GGG ннннн \\
\hline $4 \mathrm{~W} 7 \mathrm{~T}$, & $\mathrm{fb} 15$ & GGGGHT & EEEEEETT & TTEEEEEE $\mathrm{S}$ & HHHHHH & TTTSSTTSSH \\
\hline $4 \mathrm{~W} 7 \mathrm{~T}$, & $\mathrm{ff} 14 \mathrm{sb}$ & GGGHHT & EEEEEETT & TTEEEEEE $\mathrm{S}$ & НнНнНH & TTTT SS HH \\
\hline & & 116 & & & & \\
\hline Amino & Acid & KAFMEALQAG & ADISMIGQFG & VGFYSAYLVA & EKVTVITKHN & DDEQYAWESS \\
\hline 2 WI6, & $\mathrm{fb} 15$ & НнннннНнТТ & GGGGGTTT & GGGGGGGTE & EEEEEEEE $T$ & TS EEEEEE \\
\hline 2 WI6, & $\mathrm{ff} 14 \mathrm{sb}$ & НнHнHн ТT & GGGGGGTT & GGGGGGGTE & EEEEEEEE T & TS EEEEES \\
\hline 2Вт0, & fb15 & НHНHНHНHTT & GGGGGGGT & GGGGGGGTE & EEEEEEEE T & TS EEEEE \\
\hline 2Вт0， & $\mathrm{ff} 14 \mathrm{sb}$ & НHнHнHнHтT & GGGGGTTT & GGGGGGGTE & EEEEEEEE T & TS EEEEEEE \\
\hline $4 \mathrm{~W} 7 \mathrm{~T}$, & $\mathrm{fb} 15$ & НнНнНнННТТ & GHHHHHT & SGGGGGGTE & EEEEEEEE T & TS EEEEE \\
\hline $4 \mathrm{~W} 7 \mathrm{~T}$, & $\mathrm{ff} 14 \mathrm{sb}$ & НHНHНHНHTT & GGGGGGTT & GGGGGGGTE & EEEEEEEE $T$ & TS EEEEEE \\
\hline & & 166 & & & & \\
\hline Amino & Acid & AGGSFTVRTD & TGEPMGRGTK & VILHLKEDQT & EYLEERRIKE & IVKKHSOFIG \\
\hline 2 WI6, & fb15 & SSSEEEEEE & SS SEEE & EEEEE TT G & GGG нннннН & нннннттТ $\mathrm{S}$ \\
\hline 2WI6, & $\mathrm{ff} 14 \mathrm{sb}$ & STSEEEEEE & SEEE & EEEEE GGGG & GGGSHHHHHH & ннНннттT $\mathrm{S}$ \\
\hline 2ВT0, & $\mathrm{fb} 15$ & SSSEEEEEE & SEEE & EEEEE GGGG & GGGSHHHHHH & нннннттТ \\
\hline 2Вт0, & $\mathrm{ff} 14 \mathrm{sb}$ & TTSEEEEEE & SEEE & EEEEE GGGG & GGG НннннН & HнHнHSTT $\mathrm{S}$ \\
\hline $4 \mathrm{~W} 7 \mathrm{~T}$, & $\mathrm{fb} 15$ & SSSEEEEEE & SEEE & EEEEE GGGG & GGGSHHHHHH & НнНнН $\mathrm{S} \quad \mathrm{S}$ \\
\hline $4 \mathrm{~W} 7 \mathrm{~T}$, & $\mathrm{ff} 14 \mathrm{sb}$ & SSSEEEEEE & SEEE & EEEEE GGGG & GGGSHHHHHH & НнНнНТTТ \\
\hline & & 216 & & & & \\
\hline Amino & Acid & YPITLFVEK & & & & \\
\hline 2WI6, & $\mathrm{fb} 15$ & $S$ EEE & & & & \\
\hline $2 \mathrm{WI} 6$, & $\mathrm{ff} 14 \mathrm{sb}$ & $\mathrm{S} \mathrm{EE}$ & & & & \\
\hline & & & Sheet & ts: E (Parallel & Beta), B (Ant & i-parallel Beta) \\
\hline 2Вт0, & fb15 & S EEE & Helix: & : G (3-10), H ( & Alpha), I (Pi/3 & 3-14) \\
\hline 2ВT0, & $\mathrm{ff} 14 \mathrm{sb}$ & $S$ EEE & Turn: & $\mathrm{T}$ (Turn), S (Be & end), None & \\
\hline $4 \mathrm{~W} 7 \mathrm{~T}$, & $\mathrm{fb} 15$ & $S$ EE $S$ & & & & \\
\hline $4 \mathrm{~W} 7 \mathrm{~T}$, & $\mathrm{ff} 14 \mathrm{sb}$ & S EEE & & & & \\
\hline
\end{tabular}

Figure S6: Average secondary structure assignment of the Hsp90 protein for each MD simulation using the DSSP method [104]. 


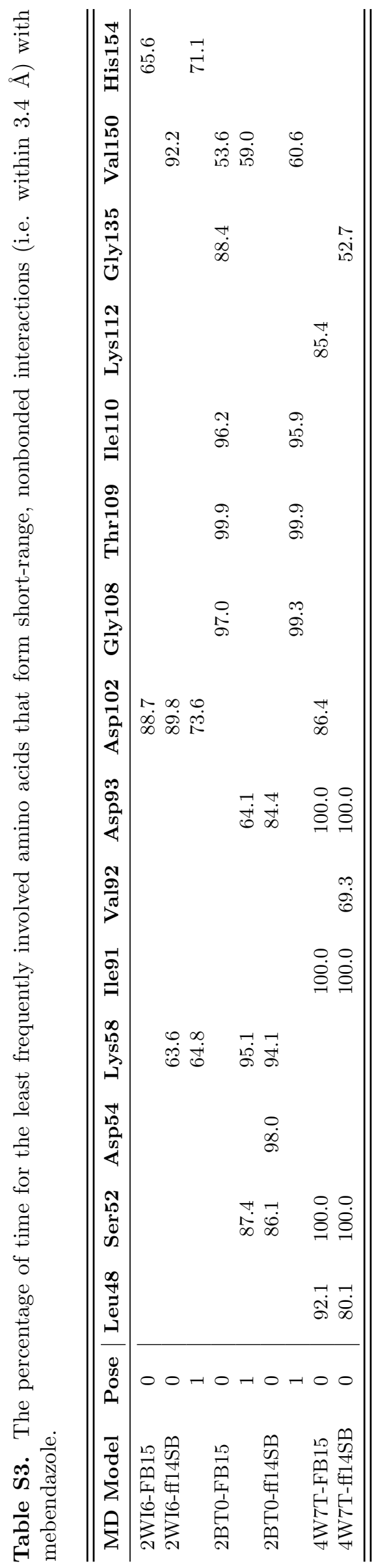

